\title{
Why SPAC investors should listen to the market*
}

\author{
Tim Jenkinson \\ Said Business School, Oxford University and CEPR \\ Miguel Sousa \\ Said Business School, Oxford University
}

\begin{abstract}
Special purpose acquisition companies (SPACs) have raised around $\$ 22$ bn from investors since 2003, and comprised $20 \%$ of total funds raised in US IPOs in 2007. SPACs are interesting structures - allowing investors a risk-free option to invest in a future acquisition. However, we show that more than one-half of approved deals immediately destroy value. Investors, who can observe the market's view of the proposed deal, as well as that of the founders, should listen to the market, since the extreme incentives faced by the SPAC founders create corresponding conflicts of interest. We propose a simple, observable rule - based on market prices - which investors should heed.
\end{abstract}

Key words: SPACs, cash shells, IPOs, private equity

$$
\text { JEL: G14, G34 }
$$

Draft: February 2009

\footnotetext{
*Comments welcome to tim.jenkinson@sbs.ox.ac.uk or miguel.sousa@sbs.ox.ac.uk
} 
But the most strange of all, perhaps, was "For an Undertaking which shall in due time be revealed." Each subscriber was to pay down two guineas, and hereafter to receive a share of one hundred, with a disclosure of the object; and so tempting was the offer, that 1,000 of these subscriptions were paid the same morning, with which the projector went off in the afternoon. Bagehot (1877, Chapter 6), writing about various securities and investment opportunities that were created during the South Sea Bubble of 1720.

\section{Introduction}

Raising money to invest in unknown opportunities has a surprisingly long heritage. Fortunately, most of the modern varieties of such funds are for more tangible purposes than those referred to in the above quotation. Indeed, in recent years this form of acquisition entity - variously known as cash-shell, blank-check company or special purpose acquisition company (SPAC) - has experienced a renaissance, raising significant amounts of capital from investors. Many prominent business figures have founded such entities, including Roland Berger, Tom Hicks, Joseph Perella, Ronald Perelman, Bruce Wasserstein and Steve Wozniak, as well as public figures such as Dan Quayle and former CIA director George Tenet. In this paper we focus on the US variant, usually referred to as SPACs, which raised $\$ 12$ billion in 2007. SPACs raise their funds through IPOs and have become a significant proportion of new issues in the US: of the 280 IPOs in 2007 , 66 were SPACs. As their name implies, SPACs are formed with the objective of finding an existing company to acquire, and so can be thought of as single deal private equity funds, especially as they use similar financial techniques when structuring the acquisition.

However, SPACs differ from private equity funds in important ways. Private equity investors commit capital to the fund, which is then drawn down as deals are found. The private equity executives have discretion over which companies to invest in. The companies acquired are, in general, either private or taken private, and so market prices of the funds are not normally available, and investors cannot easily sell their holding, or 
pass on their commitment, during the life of the fund. ${ }^{1}$ And the investors pay the private equity executives a (significant) annual management fee and a share - almost always $20 \%$ - of the profits on the fund. SPACs differ on all these dimensions. Investors hand over the money up-front, many months before the ultimate acquisition. The SPACs themselves conduct an IPO and so market prices can be observed, in particular after an acquisition has been announced. Investments in SPACs can be sold at any time. Investors generally pay very minimal management fees but allocate the SPAC founders a share also usually $20 \%$ - of the capital value of any acquisition that is made. And investors vote on any proposed acquisition, with the option that they can take out their money if they are against the deal.

As this broad summary makes clear, SPACs are structured to create extreme incentives on the part of the founders, as their payoffs are dependent on completing an acquisition. Since they receive a proportion of the capital value, they can still make money even if the acquisition is value destroying. Viewed from this perspective SPACs sound a very bad idea. But this misses some of the benefits of the SPAC structure, which explain their growth and popularity with investors, in particular hedge funds. The typical SPAC structure, which we explain in more detail in the next section, provides investors with essentially a risk-free, liquid investment as well as an option to participate in any future acquisition. In the period from the IPO until the decision is made whether to proceed with the proposed acquisition or return funds to investors, most of the funds are kept in trust and invested in government securities. When a potential acquisition is announced, market prices move to reflect investors' views of the value of the deal. Thereafter investors can exercise their option: to stay invested and agree to the deal, sell their shares into the market, or vote against the deal and get their money back. Provided the market prices are informative, investors should be able to make profits (when the market indicates the acquisition is good) and avoid losses (when the market price falls below the liquidation value of the trust).

\footnotetext{
${ }^{1}$ A number of private equity funds are established as companies that are quoted on stock markets, or have significant feeder funds that are quoted, but these are the exception rather than the rule. Similarly, although secondary sales of private equity partnership interests take place, these are strictly limited by SEC rules, as well as being subject to the agreement of the fund managers.
} 
We show in this paper that market prices are informative, and that simple trading strategies can yield significant essentially risk-free profits to investors. However, we also show that more than one-half of the acquisitions were approved by shareholders despite the market correctly indicating ex ante that they would be value destroying. We discuss why such acquisitions were consummated, by analyzing trading behavior around the date of the vote to acquire or liquidate. We find examples of extraordinary behavior on the part of the SPAC founders and the management of the potential acquisition target. By constructing portfolios of "good" and "bad" acquisitions - from market data that could be observed ex ante, we show that investors who went along with the SPAC founders' proposals rather than listening to the market suffered average cumulative returns of $-39 \%$ within six months, rising to $-79 \%$ after a year. ${ }^{2}$ Our results are particularly relevant to investors in the 65 US SPACs which, at the time of writing, have raised $\$ 12.8$ billion but have yet to consummate an acquisition.

However, although we find that many SPACs are bad investments, our conclusion is not that the SPAC structure is fundamentally flawed. The ability to observe market prices once acquisitions are announced gives investors valuable information that can be used to inform their voting decisions. And being able to vote on each acquisition gives investors much more control than in conventional private equity funds. Furthermore, by creating listed pools of capital into which acquisitions can be transferred, the uncertainty (over pricing or the ultimate success of the IPO) and costs (in terms of IPO discounts) typically associated with going public can largely be avoided. Indeed, in the current environment many companies held by conventional private equity funds are likely to seek SPACs as potential exit routes. This is not to say that the current economics of SPACs with the large equity stakes accruing to the founders - will necessarily persist. But this form of private equity funding looks likely to endure, and probably grow. Although the focus of this paper is on US SPACs, there has been a similar impressive growth in capital -raising by SPACs in Europe.

\footnotetext{
${ }^{2}$ As we explain later, these figures are calculated on an equally-weighted basis, unadjusted for market returns. In terms of buy-and-hold returns, the average return was $-30 \%$ after 6 months and $-46 \%$ after 1 year.
} 
The remainder of the paper is structured as follows. In the next section we briefly explain the structural features of SPACs. In section 3 we explain our sample and how it relates to the universe of SPACs that have been raised in the US. We then, in section 4 , focus in on the post-announcement period during which market prices react to a proposed acquisition, and investors decide on their action. We show how market prices react to the announcement, and how the decision to invest or liquidate relates to market prices. Within an event study framework, we then analyze how the returns for the good and bad portfolios evolve. Section 5 considers why the bad SPACs are allowed to make their acquisition, rather than being liquidated by investors. Section 6 concludes.

\section{How SPACs work}

\subsection{The IPO, ownership and founders' incentives}

A SPAC is a company founded by a small group of sophisticated investors or industry experts (henceforth we refer to this group as the founders), which at the time of going public has neither business operations nor any clear intention of future potential acquisitions (otherwise these would need to be declared in the prospectus). The sole purpose of a SPAC is to find an existing company to acquire through a merger, asset acquisition or similar business combination. Immediately following the IPO the company simply consists of the founders and a healthy bank account (containing the IPO proceeds); consequently, SPACs are sometimes referred to as blank-check companies or cash-shells.

A large proportion - typically between $85 \%$ and $100 \%$ - of the net proceeds of the IPO are placed in a trust and cannot be used by the founders until an acquisition is made. ${ }^{3}$ The trust invests in US short-term government securities and so earns interest. Up to $15 \%$ of the proceeds from the offering are used to cover the underwriter's discount,

\footnotetext{
${ }^{3}$ SPAC IPOs can differ in various ways, but certain characteristics are common to most offerings. The typical structure involves the offering of a unit, at a price of $\$ 6$ or $\$ 8$ per unit, consisting of common stock and one or two additional warrants for common stock. Typically, each warrant entitles the holder to purchase one share at a price of $\$ 5$ or $\$ 6$ each and becomes exercisable only after the completion of a business combination. The common stock and the warrants trade separately shortly after the IPO.
} 
expenses of the offering and for working capital purposes. ${ }^{4}$ For more detail on the legal aspects of SPACs see Hale (2007) or Sjostrom (2008).

The founders typically receive no remuneration while they search for a potential acquisition. However, they own a significant proportion of the equity, which they acquire at nominal cost before the IPO; we refer to these as the founder shares. ${ }^{5}$ We refer to the shares sold at the IPO as public shares, to differentiate them from the founder shares. After the completion of the IPO the founders hold around $20 \%$ of the total outstanding shares (or slightly less if the over-allotment option - usually $15 \%$ of the offering - is exercised by the underwriter). All the founder shares are deposited into an escrow account with the underwriter who votes these shares with the majority of the public shareholders in connection with any proposed acquisition. However, it is important to note that there is nothing to stop the founders buying public shares in the market, and in such cases the rights of such shares are identical whether owned by the public or the founders. We return to this issue in section 5.

A typical timeline for SPACs is presented in Figure 1. The founders usually have 18 months after the closing of the IPO to recommend an acquisition in the form of a letter of intent or agreement to enter into a business combination. This acquisition must be concluded within 24 months of the IPO. If these milestones are not met, the entire trust account, including interest, along with any remaining net assets of the SPAC is then distributed to the public shareholders. The founders' shares are typically locked-up for three years after the IPO. ${ }^{6}$ In the event the SPAC is liquidated, having failed to acquire a business within the deadline, the founders do not participate in any liquidation distribution with respect to shares acquired before the IPO.

\footnotetext{
${ }^{4}$ If $100 \%$ of the cash generated in the IPO is placed in the trust, expenses could be covered by, for instance, the interest earned by the trust, private placements to management on the date of the offering, or class B shares that have no claims on the trust distribution if the SPAC is liquidated.

${ }^{5}$ In most SPACs, the founders commit to purchase warrants in a private placement on the date of the offering or in the secondary market after the warrants trade separately.

${ }^{6}$ These shares may be released if after the completion of a business combination, the SPAC enters into a transaction in which the shares of all of its common stockholders are exchanged for shares of the target company.
} 
Therefore, although the founders have a significant stake in the SPAC, this will be worthless if the business combination is not consummated. These factors create extreme financial incentives to complete a business combination whether or not it is the optimal choice, as their payoffs are dependent on completing an acquisition. Consequently, a critical aspect of the SPAC structure is that public shareholders decide whether on not a proposed acquisition should be approved. In making this decision they are able to observe the market prices.

\subsection{Between the IPO and the announcement of a potential acquisition}

Between the IPO and the day the letter of intent or agreement is announced (the announcement date), the value of the SPAC shares derives from their claim on the trust monies. The trust value at date $t$ is equal to $\mathrm{TV}^{0} \mathrm{x}\left(1+\mathrm{r}_{\mathrm{f}}\right)^{\mathrm{t}}$, where $\mathrm{TV}^{0}$ is the initial trust value, $t$ is the time since the IPO and $r_{f}$ is the implicit risk-free rate. We cannot observe $r_{f}$ (since we do not know exactly what mix of government securities are purchased) but it can be estimated by comparing $\mathrm{TV}^{0}$ with the last published trust value per share which we denote $\mathrm{TV}^{\mathrm{T}}$ (often the last quarterly statement before the decision date). If the trust value at the decision date is not available, $\mathrm{TV}^{\mathrm{T}}$ can then be rolled forward at the implicit risk free rate until the decision date. This estimate of the trust value per share will play an important role in the remainder of this paper.

Given the structure of SPACs, the share price should never be below, apart from transaction and liquidity costs, ${ }^{7}$ the trust value per public share. The price should also not be much higher than the trust value, since until the public announcement of a letter of intent or agreement nothing is known about the deal. Thus, in the absence of information leakage, between the first day of trading after the IPO and the announcement date, the SPAC share price should closely track the trust value. From the viewpoint of public shareholders, until the announcement date, SPACs are essentially government bonds, not only because the public shares represent money held in a trust invested in US short-term

\footnotetext{
${ }^{7}$ Although the shares are publicly traded their turnover tends to be very low, especially in the period before the announcement date.
} 
government securities, but also because (as explained below) they can redeem the shares and get their money back at the decision date, even if the acquisition is approved.

\subsection{Between the announcement of a potential acquisition and the decision date}

Once a letter of intent or agreement is announced, the public shareholders can value the proposed deal and exercise their option: to stay invested and agree to the deal; sell their shares into the market; or wait for the shareholder meeting (the decision date), vote against the deal and get their money back. The SPAC share price between the announcement date and the decision date will reflect investors' assessment of the value of the deal. During this period the share price should reflect three circumstances. First, as in the pre-announcement period, the share price should not be far below the actual trust value, even if the deal is value destroying, since the public shareholders can always vote against and obtain the trust value. Second, if investors believe the proposed deal creates value, the share price should increase. Third, even if the deal does create value there will be a (negative) dilution effect, because, if the acquisition is approved, outstanding warrants became exercisable and the shares held by the founders (around 20\%) will have the same rights ${ }^{8}$ as the public shares.

Given the obvious conflicts of interest facing the founders, the public shareholders control the outcome. The acquisition can only proceed if two conditions are satisfied: (1) a majority of the public shares of common stock are voted in favor of the deal, and (2) not more than 20 percent of the public shares vote against and exercise their right to convert their stock into a pro rata share of the trust fund (even if a majority vote in favor of the deal). The second condition reflects the fact that public shareholders might vote against the deal but not necessarily demand their share of the trust fund, and the need for the funds available for the acquisition to be reasonably close (within 20\%) to the amount originally raised. Otherwise the acquisition is rejected, the SPAC is liquidated and the proceeds held in the trust account, including interest, will be distributed to the public shareholders. Therefore, since public shares can always be redeemed and receive a

\footnotetext{
${ }^{8}$ Even if the shares are subject to a lock-up agreement, if an acquisition is approved, from the decision date the shares have the same rights as the other shares, for instance, in respect of dividends.
} 
pro rata of the trust fund, ${ }^{9}$ even if the acquisition is approved by the other shareholders, investing in a SPAC until the decision date is essentially a risk-free investment with an upside option value if a good deal is found by the SPAC founders.

\subsection{At decision date}

At decision date the SPAC share price should reflect the market evaluation of the proposed deal (value added less dilution effect) and should never be far below, apart from transaction and liquidity $\operatorname{costs}^{10}$, the actual trust value. If the share price is equal to (or slightly below) the actual trust value per share, the market is evaluating the proposed deal as value destroying for the public shareholders, so rationally the SPAC should be liquidated. Conversely, if the share price is higher than the actual trust value per share it means the deal is expected to create value (even given the dilution effect) and so, rationally, the acquisition should be approved. This provides a simple decision rule for investors. We show later that the actual decisions in many cases do not follow this rule: many acquisitions are approved even when the market signals that they will create no value. We construct portfolios of "good" and "bad" SPACs according to this simple decision rule and show how the bad SPACs lose spectacular amounts of money for the public shareholders. In section 5 we provide an explanation of why bad SPACs are not liquidated. However, before turning to these issues we first explain the data that we use.

\section{Data and sample}

Since August 2003, U.S. SPACs have raised more than $\$ 22$ billion in 161 initial public offerings. The development of the market, in terms of both the number of new SPACs and the average amount raised, is evident in Figure 2. From a single SPAC raising \$24 million in 2003, the market peaked in 2007 when 66 SPACs raised $\$ 12$ billion. These

\footnotetext{
${ }^{9}$ The SPAC investors only have to vote against the proposed deal at the shareholder meeting (either in person or by proxy) and express their desire to redeem their shares.

${ }^{10}$ If the acquisition is rejected, although normally it takes one to two months, it can take up to 6 months to liquidate the SPAC and distributed all the proceeds to the investors.
} 
constituted a significant proportion of the total IPO market: $24 \%$ of US IPOs were SPACs in 2007.

In this paper we focus on the post-acquisition share price performance of SPACs that approved and consummated an acquisition. We collect trading price data up to the end of December 2008. In order to allow for at least six months of post-acquisition trading, we focus on SPACs where the decision date to approve or reject the acquisition occurred by the end of June 2008. 60 SPACs satisfied this condition, which comprises all SPACs that conducted an IPO between August 2003 and June 2006 (recall that the decision date has to occur within two years of the IPO).

We gathered information on our sample from CapitalIQ: the management holdings before and after the IPO, the SPAC size (number of units and offering price), the common stock and warrants in each unit, share prices, the actual amount that was invested in the trust fund after the IPO, whether the over-allotment had been exercised, the announcement date, the decision date and the trust value at the decision date.

We exclude two companies from our analysis due to data inconsistency. ${ }^{11}$ Table 1 presents descriptive statistics of the remaining 58 SPACs that form the sample for the remainder of this paper. The IPOs raised an average of $\$ 69$ million, with between $85 \%$ and $100 \%$ (average of $91.3 \%$ ) of the proceeds being held in the trust fund. The founders hold an average of $19 \%$ of the common stock immediately after the IPO. On average, it takes 378 days to announce a potential acquisition and a further 264 days to complete, reject or abandon the deal. ${ }^{12}$ At the announcement date, on average, the share price is $99.7 \%$ of the estimated trust value, rising to $107.3 \%$ of the trust value at the decision date.

\footnotetext{
${ }^{11}$ The two excluded SPACs are Mercator Partners Acquisition Corporation, which went public on April 2005, and Global Services Partners Acquisition Corporation, which went public on April 2006. In these cases we could not reconcile the reported share prices with the trust value.

${ }^{12}$ As can be seen from Table 1, there is considerable variation in the time taken to source and consummate deals. The quickest announced deal was the proposed acquisition by International Shipping Enterprises of Navios Maritime Holdings on 10 February 2005, just 2 months after the IPO. Feldman (2006) notes that this raised alarm bells at the SEC, because "SEC believed that this meant conversations must have taken place with the target company prior to being public.” The record for cold feet goes to Good Harbor Partners who, on 15 November 2007, announced the termination of their proposed deal in the security industry just two month after they had announced it.
} 
Of these 58 SPACs, 43 approved and consummated an acquisition; 15 were liquidated and the money held in the trust was returned to the investors. As Table 1 shows, the SPACs that made an acquisition were somewhat smaller, raising an average of $\$ 65 \mathrm{~m}$ at the IPO compared with $\$ 80 \mathrm{~m}$ for those that were ultimately liquidated. The proportion of the proceeds that were held in the trust fund, and the management stakes post-IPO, were very similar across the two groups. One dimension upon which the consummated deals differ from the liquidated is the length of time it took for the founders to propose a deal: 364 days for SPACs that made acquisitions compared with 420 days for those that were liquidated, suggesting that deals that convince investors are found sooner. Furthermore, we show in the next section that "good" deals are found much quicker than "bad" deals.

At the decision date, all 15 SPACs that were liquidated had a share price below the estimated trust value, with an average ratio of $95.9 \%$ (and, as expected, a narrow range of $90.7 \%$ to $99.2 \%$ ). In these cases the investors heeded the advice of the market and rejected the deals. For the 43 SPACs where investors voted in favor of the deal, the share price at the decision date was, on average, $110.7 \%$ of the trust value per share. However, this average hides much interesting variation: in some cases the market is clearly signaling its enthusiasm for the deal, with the ratio of the share price to the trust value hitting a maximum of $224 \%$ for one SPAC. However, in a surprising number of cases the share price at the decision date is actually below the trust value: the extreme case being one SPAC whose price was only $79 \%$ of the trust value. Why did investors agree to the deal, when they could have voted against and obtained the trust value? Could SPAC investors make superior predictions of the future performance than the market? In the next section we analyze the performance of the 43 SPACs that completed a deal, using estimated trust values and the share price performance at the decision date to construct two portfolios, according to whether the market signals were positive or negative. This provides an observable decision rule for investors, and we estimate the returns on these portfolios. 


\section{Empirical analysis}

For the 43 SPACs where the proposed deal was approved by investors we can calculate the subsequent returns after the decision date. In these cases, the SPACs became normal companies, with assets and operating businesses, and with common shares quoted on the stock exchange. Like Jog and Sun (2007), on average we find a large negative return after the acquisition is made. As can be seen in Figure 3, on an equally weighted basis, SPACs produced an average cumulative return of around $-24 \%$ after six months. Market weighting has little impact on these results, so henceforth we focus on equally weighted portfolios. Indeed, the poor performance persists beyond six months: for the 37 companies with 52 weeks of trading data available, the average cumulative return is $-55 \%$ after one year. On the face of it, this is a remarkable result, as it appears that SPAC shareholders consistently approve value-destroying transactions.

However, this is not true for every SPAC that made an acquisition. To conduct our analysis, we first split our sample of 43 SPACs in two sub-samples, which we call the Good SPACs and the Bad SPACs. The Bad SPACs are those where investors approved a deal when the price at the decision date - or, strictly, the closing share price on the day before $^{13}$ the decision date - was below the trust value per share. Investors, therefore, went against the view of the market, which had valued the deal as value destroying. Recall that the investors who approved these deals could have voted against and received their proportion of the trust fund. The Good SPACs are obviously those where investors approved a deal when the share price at decision date was higher than the trust value per share. Thus, provided the market prices are informative, they approved deals that were expected to create value, even after the dilution effects.

Of our sample, 20 SPACs were Good and 23 were Bad. Table 2 compares these sub-samples. In terms of funds raised at the IPO, the two groups are very similar in size, and hold a similar proportion (around 90\%) of the IPO proceeds in the trust fund. The founders take longer to announce a proposed deal in the case of Bad SPACs (393 days vs.

\footnotetext{
${ }^{13}$ We use the closing price on the date before the decision date because we cannot observe intra-day prices for all SPACs, nor when the decision meeting took place during the decision day. The closing price on the day before the decision date is the last easily observable price before the vote.
} 
331 days for Good SPACs), although the deal is then approved in less time (246 days vs. 300 after the announcement).

Regarding the share price at the announcement date, for the Good SPACs this was, on average, 104.1\% (median 99.4\%) of the trust value per share compared with 97.7\% (median of 97.7\%) for the Bad SPACs. Not surprisingly, the main difference appears at the decision date, once investors have evaluated the proposed deal: for the Good SPACs the share price was, on average, $130.6 \%$ of the trust value compared with 93.4\% for the Bad SPACs.

All the reported figures so far have been averages across groups of deals. To illustrate how deals evolve, we present in Figure 4 the share price performance between the announcement and decision dates, along with the estimated trust value, for typical Good and Bad SPACs. Chardan China Acquisition Corporation announced its acquisition in November 2004. Until this date, the share price had, as expected, been close to the estimated trust value. Immediately after the announcement, the share price jumped significantly and peaked at about twice the trust value, before falling back a little at the decision date. Clearly the market thought the deal would create value. In contrast, when Global Logistics Acquisition Corporation announced its potential deal in May 2007, the share price barely responded, and remained below the trust value until the decision date. Indeed, the share price collapsed on the decision date, probably reflecting forced selling by investors who were incapable of attending the meeting or submitting their votes by proxy, since only those who register votes against the deal can obtain their pro-rata share of the trust account.

These patterns of performance between the announcement and decision dates remain when constructing portfolios of Good and Bad SPACs, as can be seen in Figure 5. For the portfolio of Good SPACs there is an immediate share price response around the announcement date, and the premium to the trust value drifts steadily upwards, reaching an average of $131 \%$ of the trust value at the decision date. Since the gap between the announcement and decision date differs across SPACs we compute indices based on each date. For the Bad SPACs the share price remains stubbornly below the trust value, with a noticeable drop in the last few days before the decision date. What these charts illustrate is that the dye was cast - in terms of market perception of the proposed deals - almost 
immediately after the announcement. Investors could observe, for many weeks before the decision date, consistent premia for the Good SPACs and consistent trading below trust value for the Bad SPACs. Were these signals informative regarding future postacquisition performance?

To answer this question we employ an event-study methodology, using the acquisition as the event. We line stocks up in event time, and analyze their returns over the 26-week period after the acquisition date.

Figure 6, Panel A, presents raw returns for each group. It can be seen that Bad SPACs perform poorly immediately after the decision date and continue to fall throughout the first six months of trading. The average cumulative return is $-39 \%$ after 26 weeks, and the cumulative returns are statistically different from zero from the second week after the acquisition. These miserable returns continue beyond six months: the average cumulative return is $-79 \%$ after one year. ${ }^{14}$ In contrast, the raw performance of the Good SPACs is essentially flat for the first 26 weeks after the decision date, at which point the average cumulative return is just $-6.2 \%$. At no point in the first six months is the cumulative raw return for the Good SPACs statistically different from zero.

In Panel B of Figure 6 we risk-adjust the returns by computing cumulative abnormal returns (CARs) using the single-factor CAPM. We use the Russell 1000 as the market index, and use two options for the $\beta$ parameter. First, we use a simple market model with all SPAC betas equal to 1 . Alternatively we use industry betas based on the SPAC sector after the acquisition. ${ }^{15}$ Clearly, the share price performance prior to the announcement date cannot be used (as the company has no operating business), and the period between the announcement date and the decision date is both too short to compute firm-specific betas and, arguably, uninformative for the Bad SPACs, whose share price is being dominated by the trust value.

\footnotetext{
${ }^{14}$ Four Bad SPACs do not have 52 weeks of trading data available by the end of our data sample, and so this figure relates to the average returns for the remaining 19 Bad SPACs.

${ }^{15}$ We use industry betas calculated from the Value Line database of 7,091 US companies as of January 2005, which is in the middle of our sample period. These are available from http://faculty.insead.edu/peyer/FFE/Betas per industry based on US COMPANIES.doc.
} 
The results for the CARs are very similar to the raw returns. Good SPACs produce an essentially flat performance for the first six months after the acquisition resulting in an average CAR of $-6 \%$ after 26 weeks. Again, at no point is this statistically different from zero. Bad SPACs produce an average CAR of $-34 \%$ after 26 weeks. These results vary little depending on whether betas are estimated from industry peers or simply assumed to be unity for all SPACs, and in either case the CARs are statistically different from zero from the second week after the acquisition.

The results in this section show that the market response to the announced acquisitions was indeed informative. Investors who followed the simple, observable rule that we have analyzed in this section would have avoided the significant losses accruing to the Bad SPACs. The remaining Good SPACs traded at an average premium to the trust value of around one-third at the decision date, and performed approximately in line with the market during the first six months after the acquisition. Therefore, simple trading strategies could be executed to earn significant profits at very low levels of risk. For instance, investors who bought one share of all the SPACs in our sample on the day after the $\mathrm{IPO}^{16}$ and followed the strategy of (a) voting against and redeeming Bad SPACs (we assume they would receive their money one month after the vote) and (b) selling their stake in Good SPACs on the day before the decision date, would have earned a virtually risk-free average annualized return of $13.2 \%$. Higher returns could clearly be made by investing nearer the announcement dates in each case, since the early returns are close to Treasury Bill rates. This demonstrates the potential attraction of SPACs to investors, and why for instance, hedge funds have shown a strong appetite for such structures. However, according to our analysis more Bad deals were approved than Good, which begs the obvious question - why were the Bad SPACs not liquidated?

\footnotetext{
${ }^{16} \mathrm{We}$ focus on the ordinary equity as it is often difficult to obtain prices for the warrants. Note that this trading strategy avoids any IPO discount - the price of the ordinary equity on the day after the IPO reflects the pro-rata share of the proportion of the IPO proceeds that are held in trust. Doubtless, other profitable trading strategies could be constructed involving the warrants as well.
} 


\section{Why are bad SPACs not liquidated?}

This is a difficult question to answer definitively without knowledge of the investors' reasoning when casting their votes. However, in this section we propose an explanation based on the observed trading behavior in the days around the decision date. As described in section 2, the founders have to vote their founder shares - the 20 percent stake they acquire before the IPO - in accordance with the majority view of the remaining public shares. However, there is nothing to stop the founders, or their affiliates, buying up the public shares, whose votes count irrespective of who holds them at the decision date. Provided not more than 20 percent of the public shares vote against and exercise their right to convert their stock into a pro rata share of the trust fund, the acquisition will proceed. Therefore, there is an incentive for the founders, or their affiliates, to buy shares/votes just before the decision date, especially if they can identify potential "no" voters. ${ }^{17}$

Of course, this requires potentially significant amounts of capital on the part of the founders, or their affiliates - so who might these "affiliates" be? One obvious candidate is the company potentially being acquired, or its shareholders. By purchasing shares in the SPAC prior to the acquisition, the shareholders in the target company essentially retain a stake in the business after it is acquired, which could subsequently be sold in the market.

As an example of such tactics, consider again the case of Global Logistics Acquisition Corporation (GLAC), whose performance we presented in Figure 4. In an 8$\mathrm{K}$ filing with the Securities and Exchange Commission (SEC) dated February 8, 2008 GLAC announced that "an entity affiliated with certain of the stockholders of The Clark Group, Inc. has agreed to (...) purchase up to 820,000 shares of GLAC's common stock (...) from holders of such shares who have indicated their intention to vote against the proposal $(\ldots)$. Such shares will be in addition to the $2,380,000$ shares already purchased

\footnotetext{
17 The critical "no" voters are those investors that will be present at the decisive shareholder meeting, intend to vote against the proposed acquisition, and then elect to redeem their shares and take their pro rata share of the trust. The evidence we have noted earlier suggests some potential "no" voters are unable to attend the meeting, and so become forced sellers in the public market around the decision date.
} 
by the purchaser pursuant to an agreement entered into on February 1, 2008". GLAC eventually consummated the acquisition of The Clark Group, Inc. on February 12, 2008. But what this filing indicates is that in the two weeks before the decision date, the SPAC founders and affiliates of the company potentially being acquired purchased $3.2 \mathrm{~m}$ shares from public shareholders, thereby buying enough votes for the deal to be approved.

SEC filings show that such transactions - involving the purchase of large blocks of shares by the SPAC's founders or by the target company's stockholders, or affiliated entities - are frequently observed just before the decision meeting. Although requiring access to capital (although only for only a few days), the likely losses associated with such trades are usually dwarfed by the financial gains accruing to the founders if the acquisition goes ahead. The shares acquired could be sold just after the acquisition, because those shares are not locked-up, with the likely losses being offset by the $20 \%$ stake in the company the founders acquired at nominal cost. And if, even after buying shares from likely refusniks, the acquisition is rejected, the founders or their affiliates will get their money back, as these shares (unlike the founder shares) are entitled to a pro rata share of the trust value.

Berger (2008) also notes such behavior in the cases he studies. He notes that if the "SPAC investor does not understand or appreciate the value proposition" then the management of both SPAC and target companies have to identify investors that understand the fundamental value of a SPAC or, in the limit, buy the common stock themselves before the shareholder meeting. Of course, this is a rather different interpretation than ours. Far from not appreciating the value proposition, our evidence shows that investors were wise to be skeptical of the claims of the founders in one-half of all proposed deals. Nonetheless, the potential importance of share purchases by the founders or related parties before the decision date warrants further investigation.

To begin with we consider the evidence on share turnover in the two months prior to the decision date to see if there is any jump in trading activity. Figure 7 clearly shows an increase in turnover for Bad SPACs in the last two weeks before the decision date, which does not occur in the case of the Good SPACs. In the last week alone more than $25 \%$ of the common stock of the Bad SPACs is traded, compared with average weekly turnover of around $4 \%$ in weeks -2 to -8 . 
This significantly different behavior warrants closer analysis of the trades themselves, and for this we use the Trade and Quote (TAQ) data. The TAQ database contains intraday transactions data for all securities listed on the New York Stock Exchange (NYSE) and American Stock Exchange (AMEX), as well as the Nasdaq National Market System (NMS) and SmallCap issues. Unfortunately, most SPACs are not listed on these markets: 42 of the 58 SPACs in our sample traded on the Over-theCounter Bulletin Board. However, the remaining 16 SPACs in our sample were traded on the AMEX, and so TAQ data is available. Seven of these were liquidated, three were Good SPACs and six were Bad SPACs, according to our definitions.

The trading data for some of these SPACs is presented in Figure 8, which contain information on the individual trades, prices and the estimated trust value per share for each deal. The size of each trade is represented by a vertical bar (and measured on the right hand axis) and the price of each trade is recorded, and can be compared with the trust value. Trading days before the decision date are represented in alternating light and dark blue, and the decision date itself is represented in red. The total volume traded on each day is presented in the bar below the horizontal axis.

Panel A contains information on three of the seven SPACs that were ultimately liquidated (the remaining four SPACs demonstrate similar patterns). In these cases the share price was consistently below the trust value, and trading in the period before the decision date was limited. There seems to have been no attempt by the founders to buy shares in the run-up to the decision date, and investors were simply holding out for the trust value after the expected "no" vote. The Good SPACs are presented in Panel B. There is a little more trading activity in the days before the decision date, all of which takes place at a significant premium to the trust value, and there is little volatility in trading prices.

The real interest lies in Panel C, where trading data for the six Bad SPACs is presented. In these cases there is a huge volume of trading in the few days before the decision date, associated with a limited number of large transactions. Indeed, the size of some of these transactions means that the scales on the graphs have to differ significantly. Moreover, for many of these larger transactions, the shares were traded at a price equal to the trust value per share and significantly higher than the prevailing market price. For 
instance, in the case of Healthcare Acquisition Corporation, around $28 \%$ of the shares were traded in the two days prior to the decision date, and a further $6 \%$ block was the first trade on the decision day itself (almost certainly before the vote was taken). The correlation between the size of the trade and the spikes in the transaction price up to the trust value is striking (and is reassuring evidence that our constructed trust values - which play a key role in our classification of SPACs - are accurate). One might expect such large transactions to put downward pressure on prices if they were normal trades. But this evidence suggests strongly that these are not normal trades, but rather sales by large informed investors (hedge funds?) who know that they can get the trust value if they keep the shares and vote against the proposed acquisition, who find a willing counter-party in the founders or their affiliates who need to buy some votes at the last minute. Indeed, in some cases the last minute appears to be on the decision day itself, reflecting the fact that many votes are taken in the afternoon.

Admittedly, our sample here is small, but the similarities between the six Bad SPACs for which data exist is remarkable. In each case there is considerable price volatility before the decision, driven mainly by significant upward price spikes (to the trust value) associated with large transactions. However, in only one case do these trades result in a majority of the outstanding public shares changing hands (the atypical case is Community Bankers Trust Corporation shown in Figure 8 Panel C.6). So for most SPACs the question remains as to why the deals are approved, when the share price at the decision date is below the trust value? On this we can only speculate, in the absence of the voting records. Clearly, the main losers are those public investors who do not vote against the proposed transaction. This may be because they are (wrongly) convinced by the founders of the merits of the deal. Or it could be that some investors are simply unable, or choose not to, attend (or cast proxy votes) at the decision meeting. This is, of course, commonplace in normal public companies, where few small shareholders cast their votes, since they are able to free-ride on the information, analysis or corporate governance of other shareholders. But in the case of SPACs this is clearly an extremely dangerous and potentially costly tactic, since many of the large shareholders are baling out of the company at the last minute, and selling their shares to the founders or their affiliates. 


\section{Conclusions}

Special purpose acquisition companies are a new, and increasingly popular, type of investment vehicle, whose purpose is to find a suitable company in a particular sector to acquire. SPACs can, therefore, be thought of as single-deal private equity funds, which raise money up-front via an IPO, and use this quoted vehicle to take their target company public at the point of acquisition. For target companies, SPACs provide a potentially attractive way of raising external equity financing and simultaneously going public without the need for an IPO and the concomitant fees, expenses, uncertainty about valuation, or the seemingly inevitable underpricing of the shares (see Jenkinson and Ljungqvist, 2001). At a time when conventional private equity fund structures are increasingly being questioned - in terms of high fees, lack of liquidity and long-term commitments of capital - SPACs provide some important advantages for investors.

SPACs can be highly profitable for founders - who are often high-profile business leaders or financiers - since they are typically rewarded with $20 \%$ of the equity in the firm if an acquisition is completed. But such rich rewards are received only if shareholders vote in favor of the deal that is proposed by the founders, in the knowledge that the deal has to create sufficient value to outweigh the dilutive effect of the founders' stake. The founders are paid minimal, or zero, fees during their search for a target (in contrast to the general partners of private equity funds, who charge substantial on-going fees), and put the vast majority of the funds raised into a trust account, invested in government securities. From the viewpoint of investors, the SPAC structure provides essentially risk-free returns (minus the very modest costs of operating the SPAC), and an option to participate in any acquisition that they believe will create value. In deciding whether to support the founders, investors have the advantage of being able to observe the market's view of the proposed deal. And if they are unconvinced, investors can vote against and receive virtually all their money back. This combination of very low risk, high levels of control, and potential equity upside explains why SPACs have become very popular with investors. 
However, the extreme incentives facing the founders - whose payday depends on the proposed deal being approved, rather than it creating value for public shareholders means that investors have to assess the deal that is proposed very carefully. A critical signal available to investors is the share price reaction after the proposed acquisition is announced. In this paper we construct portfolios of "Good" and "Bad" SPACs according to a simple, observable rule based on the market price on the decision date. In our sample, investors approved $74 \%$ of deals, although, according to our rule, more than onehalf of these deals should have been rejected. We show that investors who went against the market signal lost around 39\% of their investments within 6 months, rising to losses of over $79 \%$ after 1 year. Conversely, investors who followed our simple strategy, of only supporting those deals where the market reaction was positive, reaped handsome, lowrisk profits. Therefore, we conclude that SPAC investors should listen to the market.

The rule we propose is intuitive, simple, and sufficiently obvious that we expect it may already be employed by some investors. But why, then, do investors approve so many value-destroying deals? By analyzing trading behavior around the date of the vote to acquire or liquidate, we show that in the case of Bad SPACs almost one-third of outstanding shares issued in the IPO are traded in the seven trading days before the decision to reject or approve the acquisition is taken. Using intraday data for the subset of SPACs for which TAQ data is available, we find a remarkable pattern of trading, with a small number of large transactions occurring in the last few days before the decision is taken, at prices that are not only significantly higher than the prevailing market prices, but are precisely equal to the trust value per share. These are not normal trades. The only way to rationalize such trades is vote-buying by the founders, or their affiliates, from large investors who have indicated that they will vote against the deal. The SPAC structures do not restrict such behavior, and we find regulatory filings that confirm the nature of such trades. Clearly, then, the investors who remain holders on the decision date have to be extremely careful, since conflicted parties may own a significant proportion of the voting shares. The large investors may have already headed for the exit, and so the remaining investors cannot free-ride on their information, analysis or judgment.

We conjecture that this pattern of behavior - with many value-destroying acquisitions being approved - suggests that small shareholders are not paying enough 
attention to their pivotal role in the decision. Of course, other explanations are possible including a blind faith in the value-creating skills of the founders. Whatever the explanation, the results of this paper are particularly relevant to those investors who either do not exercise their votes, or systematically vote in favor of the proposed deals. But the analysis is also relevant more generally - since the extremely poor performance of SPACs on average could potentially undermine the asset class. Our results suggest this fate would be inappropriate. 


\section{References}

Berger, R., 2008. SPACs: An Alternative Way to Access the Public Markets. Journal of Applied Corporate Finance 20, 68-75.

Feldman, D. N., 2006. Reverse Mergers. New York: Bloomberg Press.

Hale, L. M., 2007. SPAC: A Financing Tool with Something for Everyone. Journal of Corporate Accounting and Finance, 67-74.

Jenkinson, T., Ljungqvist A.P., 2001. Going Public. Oxford: Oxford University Press.

Jog, V. and Sun, C., 2007. Blank Check IPOs: A Home Run for Management. Working Paper, Carleton University.

Sjostrom, W.K., 2008. The Truth About Reverse Mergers. Entrepreneurial Business Law 2, 231-247. 


\section{Table 1: Sample descriptive statistics}

This table reports descriptive statistics for the 58 U.S. SPACs that conducted an IPO between August 2003 and June 2008. Of these, in 43 cases the shareholders voted in favour of the proposed acquisition, and in the remaining 15 cases the acquisition was rejected. The trust value is estimated assuming a constant rate of growth of the trust monies from the IPO until the decision date.

\begin{tabular}{|c|c|c|c|c|}
\hline All SPACs (58) & Average & Median & Maximum & Minimum \\
\hline SPAC size ( $\$ \mathrm{~m}$ raised) & 69.01 & 53.55 & 196.65 & 9.06 \\
\hline$\%$ of IPO procceds in the trust & $91.3 \%$ & $91.2 \%$ & $100.0 \%$ & $85.0 \%$ \\
\hline$\%$ owned by founders after the IPO ${ }^{1}$ & $19.1 \%$ & $18.5 \%$ & $35.0 \%$ & $15.3 \%$ \\
\hline$\%$ of warrants issue over common stock & $143.2 \%$ & $163.8 \%$ & $210.1 \%$ & $68.9 \%$ \\
\hline $\mathrm{N}^{\circ}$ of days between IPO and annoucement date & 378 & 412 & 602 & 62 \\
\hline $\mathrm{N}^{\circ}$ of days between annoucement date and decision date & 264 & 231 & 637 & 61 \\
\hline Share price at announcement date / Actual trust value ${ }^{2}$ & $99.7 \%$ & $97.8 \%$ & $151.5 \%$ & $91.9 \%$ \\
\hline Share price at day before decision date / Actual trust value & $107.3 \%$ & $98.8 \%$ & $224.3 \%$ & $79.0 \%$ \\
\hline SPACs that made an acquisition (43) & Average & Median & Maximum & Minimum \\
\hline SPAC size (\$mln raised) & 65.34 & 51.45 & 196.65 & 9.06 \\
\hline$\%$ of IPO procceds in the trust & $90.7 \%$ & $90.1 \%$ & $100.0 \%$ & $85.0 \%$ \\
\hline$\%$ of management after the IPO ${ }^{1}$ & $19.1 \%$ & $18.1 \%$ & $35.0 \%$ & $15.7 \%$ \\
\hline$\%$ of warrants issue over common stock & $144.5 \%$ & $163.9 \%$ & $210.1 \%$ & $68.9 \%$ \\
\hline $\mathrm{N}^{\circ}$ of days between IPO and annoucement date & 364 & 396 & 588 & 62 \\
\hline $\mathrm{N}^{\circ}$ of days between annoucement date and decision date & 271 & 235 & 637 & 140 \\
\hline Share price at announcement date / Actual trust value & $100.7 \%$ & $98.1 \%$ & $151.5 \%$ & $92.6 \%$ \\
\hline Share price at day before decision date / Actual trust value & $110.7 \%$ & $99.6 \%$ & $224.3 \%$ & $79.0 \%$ \\
\hline SPACs that were liquidated (15) & Average & Median & Maximum & Minimum \\
\hline SPAC size (\$mln raised) & 79.53 & 79.35 & 150.00 & 18.98 \\
\hline$\%$ of IPO procceds in the trust & $93.1 \%$ & $95.0 \%$ & $100.0 \%$ & $85.0 \%$ \\
\hline$\%$ of management after the IPO ${ }^{1}$ & $19.1 \%$ & $19.2 \%$ & $24.0 \%$ & $15.3 \%$ \\
\hline$\%$ of warrants issue over common stock & $139.3 \%$ & $160.6 \%$ & $181.4 \%$ & $81.1 \%$ \\
\hline $\mathrm{N}^{\circ}$ of days between IPO and annoucement date & 420 & 430 & 602 & 148 \\
\hline $\mathrm{N}^{\circ}$ of days between annoucement date and decision date & 240 & 211 & 511 & 61 \\
\hline Share price at announcement date / Actual trust value ${ }^{2}$ & $96.2 \%$ & $96.9 \%$ & $99.2 \%$ & $91.9 \%$ \\
\hline Share price at day before decision date / Actual trust value & $95.9 \%$ & $96.3 \%$ & $99.2 \%$ & $90.7 \%$ \\
\hline
\end{tabular}

1. Excludes three SPACs structured in a slightly different way with the management only having nominal common stock (less than $0.01 \%$ ) until the acquisition, but if an acquisition is approved and consummated their percentage increased considerably due to the exercise of the warrants they hold.

2. Excludes one SPAC that announced two different deals. The first was cancelled by the SPAC management without being voted by the shareholders. On the same day the SPAC management announced other deal. 


\section{Table 2 - Sample descriptive statistics, according to market signals at decision date}

This table reports descriptive statistics for the 43 SPACs that completed an acquisition, split according to whether the share price at the decision date was above or below the trust value; these are designated as GOOD and BAD acquisitions respectively. The trust value is estimated assuming a constant rate of growth of the trust monies from the IPO until the decision date.

\begin{tabular}{|c|c|c|c|c|}
\hline SPACs that made a GOOD acquisition (20) & Average & Median & Maximum & Minimum \\
\hline SPAC size (\$mln raised) & 65.56 & 36.15 & 196.65 & 9.06 \\
\hline$\%$ of IPO procceds in the trust & $90.0 \%$ & $88.4 \%$ & $100.0 \%$ & $85.0 \%$ \\
\hline$\%$ of management after the IPO & $19.2 \%$ & $17.9 \%$ & $35.0 \%$ & $15.7 \%$ \\
\hline$\%$ of warrants issue over common stock & $148.5 \%$ & $164.3 \%$ & $190.6 \%$ & $68.9 \%$ \\
\hline $\mathrm{N}^{\circ}$ of days between IPO and annoucement date & 331 & 298 & 557 & 62 \\
\hline $\mathrm{N}^{\circ}$ of days between annoucement date and decision date & 300 & 260 & 581 & 170 \\
\hline Share price at announcement date / Actual trust value & $104.1 \%$ & $99.4 \%$ & $151.5 \%$ & $94.4 \%$ \\
\hline Share price at day before decision date / Actual trust value & $130.6 \%$ & $117.7 \%$ & $224.3 \%$ & $100.8 \%$ \\
\hline SPACs that made a BAD acquisition (23) & Average & Median & Maximum & Minimum \\
\hline SPAC size (\$mln raised) & 65.15 & 55.20 & 172.50 & 17.31 \\
\hline$\%$ of IPO procceds in the trust & $91.3 \%$ & $90.3 \%$ & $100.0 \%$ & $85.2 \%$ \\
\hline$\%$ of management after the IPO ${ }^{1}$ & $19.0 \%$ & $18.7 \%$ & $22.6 \%$ & $16.6 \%$ \\
\hline$\%$ of warrants issue over common stock & $141.0 \%$ & $161.3 \%$ & $210.1 \%$ & $78.9 \%$ \\
\hline $\mathrm{N}^{\circ}$ of days between IPO and annoucement date & 393 & 456 & 588 & 94 \\
\hline $\mathrm{N}^{\circ}$ of days between annoucement date and decision date & 246 & 227 & 637 & 140 \\
\hline Share price at announcement date / Actual trust value & $97.7 \%$ & $97.7 \%$ & $105.0 \%$ & $92.6 \%$ \\
\hline Share price at day before decision date / Actual trust value & $93.4 \%$ & $96.1 \%$ & $99.9 \%$ & $79.0 \%$ \\
\hline
\end{tabular}

1. Excludes one SPACs (each sub-sample) structured in a slightly different way with the management only having nominal common stock (less than $0.01 \%$ ) until the acquisition, but if an acquisition is approved and consummated their percentage increased considerably due to the exercise of the warrants they hold.

2. Excludes one SPAC that announced two different deals. The first was cancelled by the SPAC management without being voted by the shareholders. On the same day the SPAC management announced other deal. 


\section{Figure 1: A typical SPAC Timeline}

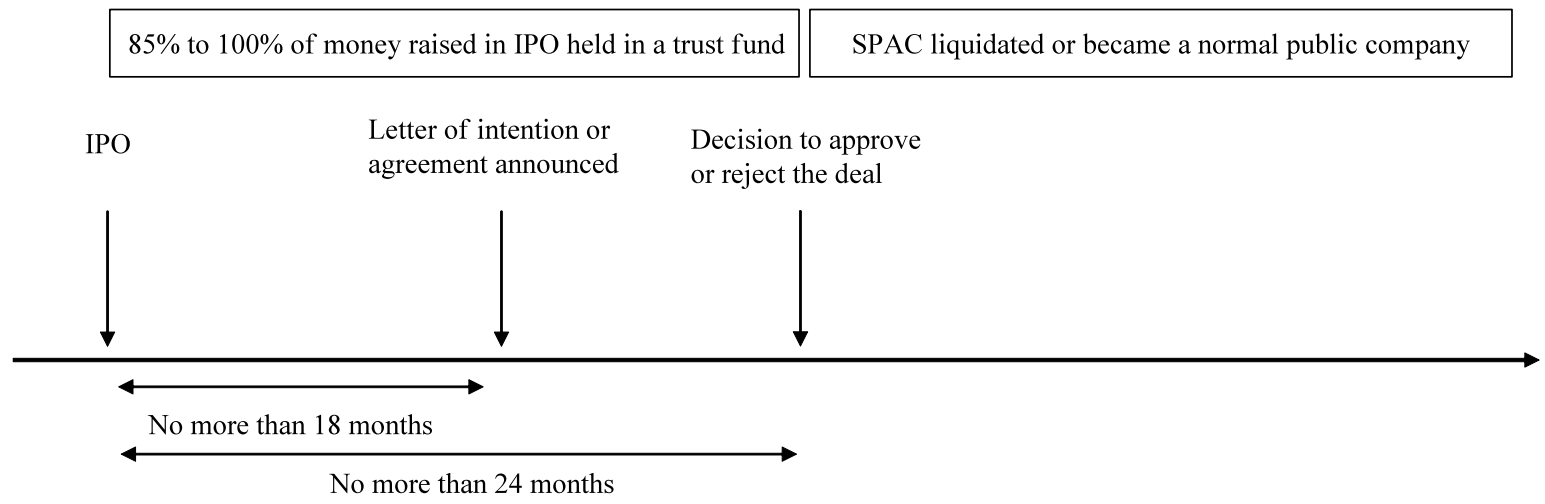

Figure 2 - the development of the U.S. SPAC sector

This figure shows how many SPACs performed IPOs on U.S. markets from 2003-08, and the average proceeds by year.

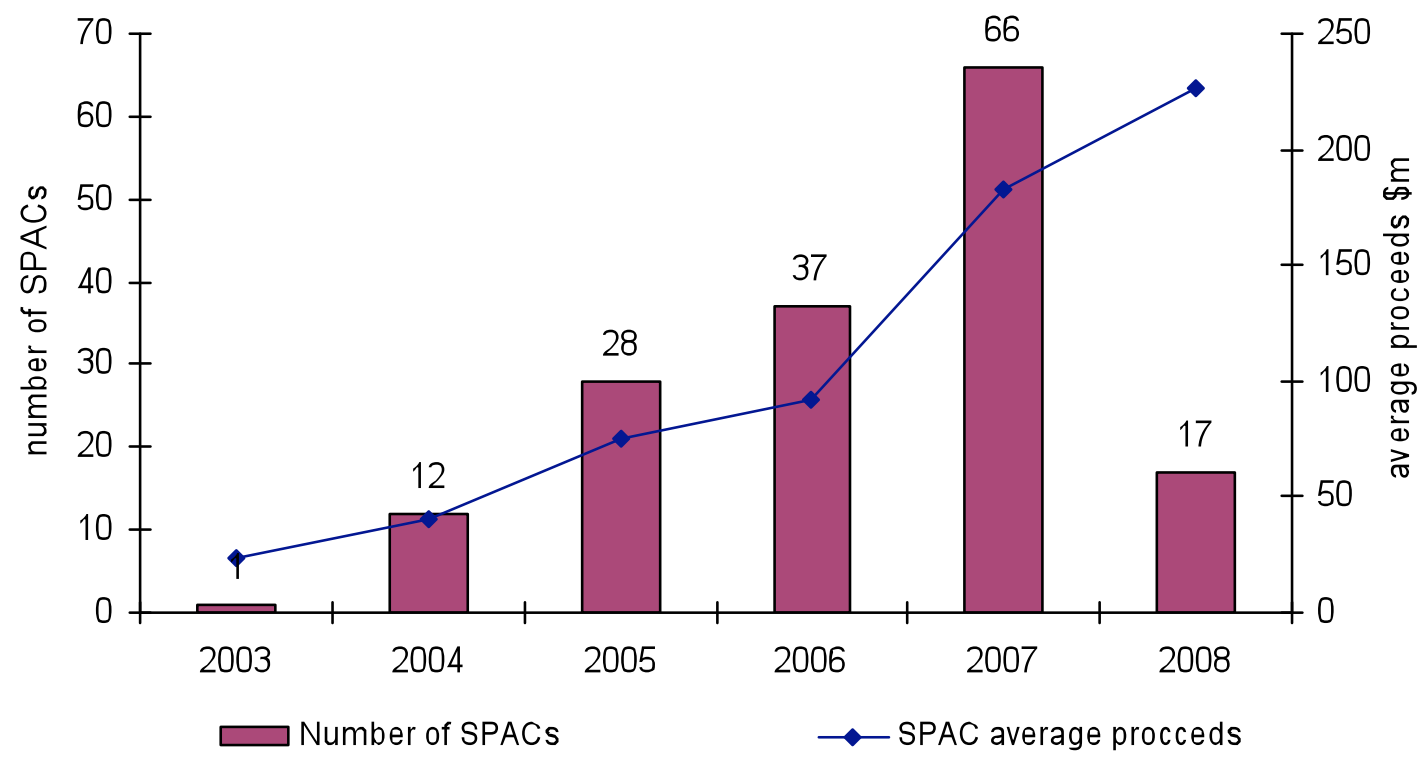


Figure 3 - Raw returns after acquisition; all SPACs that completed an acquisition

This figure reports the performance for the 43 U.S. SPACs that conducted an IPO between August 2003 and June 2008, and where investors voted in favour of the proposed acquisition. Average cumulative weekly returns are computed on an equally-weighted and market capitalization-weighted basis. For each SPAC, date 0 is the date of the vote that confirmed the proposed acquisition. The returns are simple raw returns, and are not adjusted for market movements.

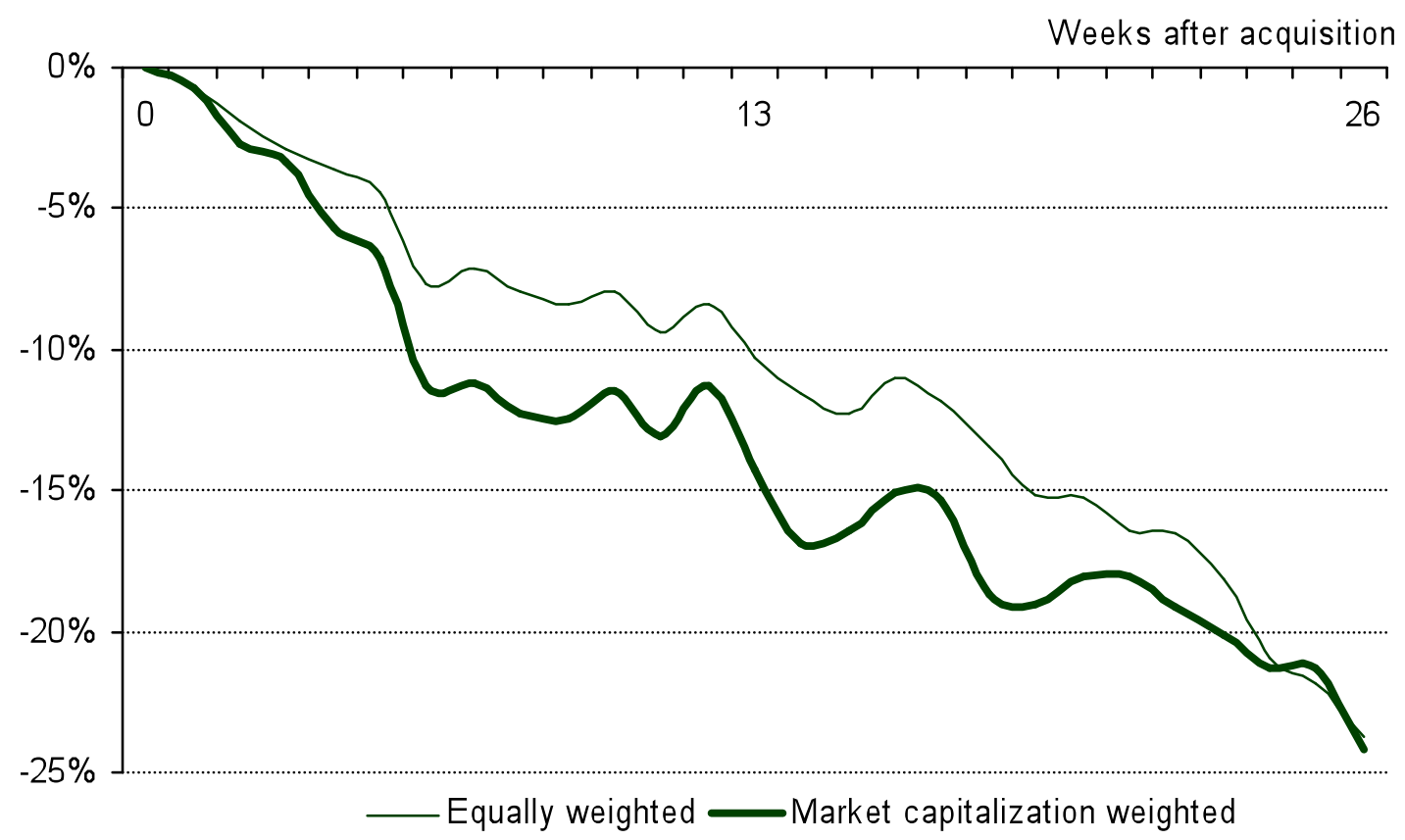




\section{Figure 4 - Examples of Good and Bad SPACs}

\section{Panel A: Chardan China Acquisition Corp}

This figure plots the Chardan China Acquisition Corp. share price from the first day of trading $\left(29^{\text {th }}\right.$ March 2004) until the decision date ( $8^{\text {th }}$ November 2005) against the trust value per share.

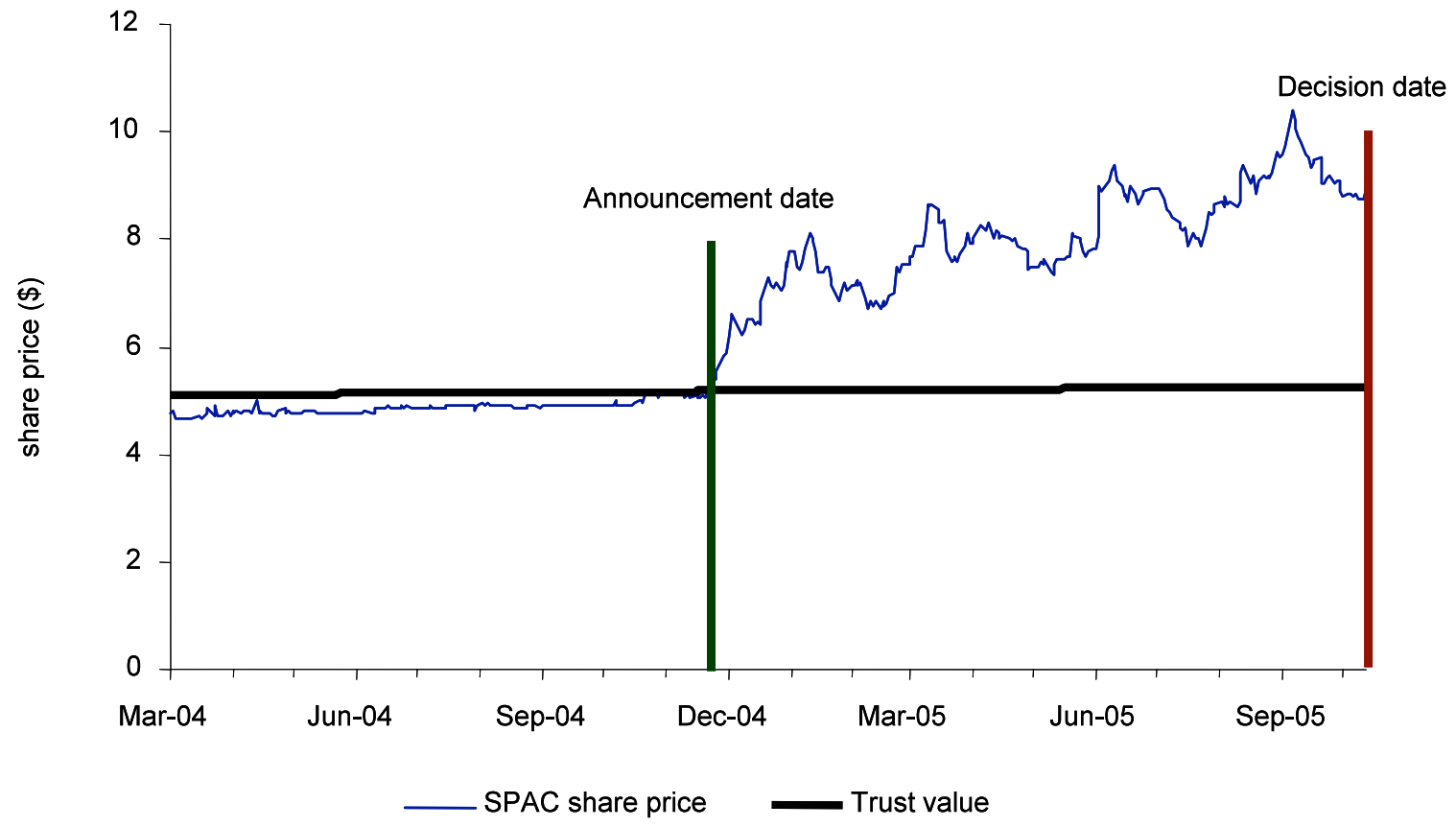

Panel B: Global Logistics Acquisition Corporation

This figure plots the Global Logistics Acquisition Corporation share price since the first day of trading $\left(21^{\text {st }}\right.$ April 2006) until the decision date $\left(12^{\text {th }}\right.$ February 2008) against the actual trust value per share.

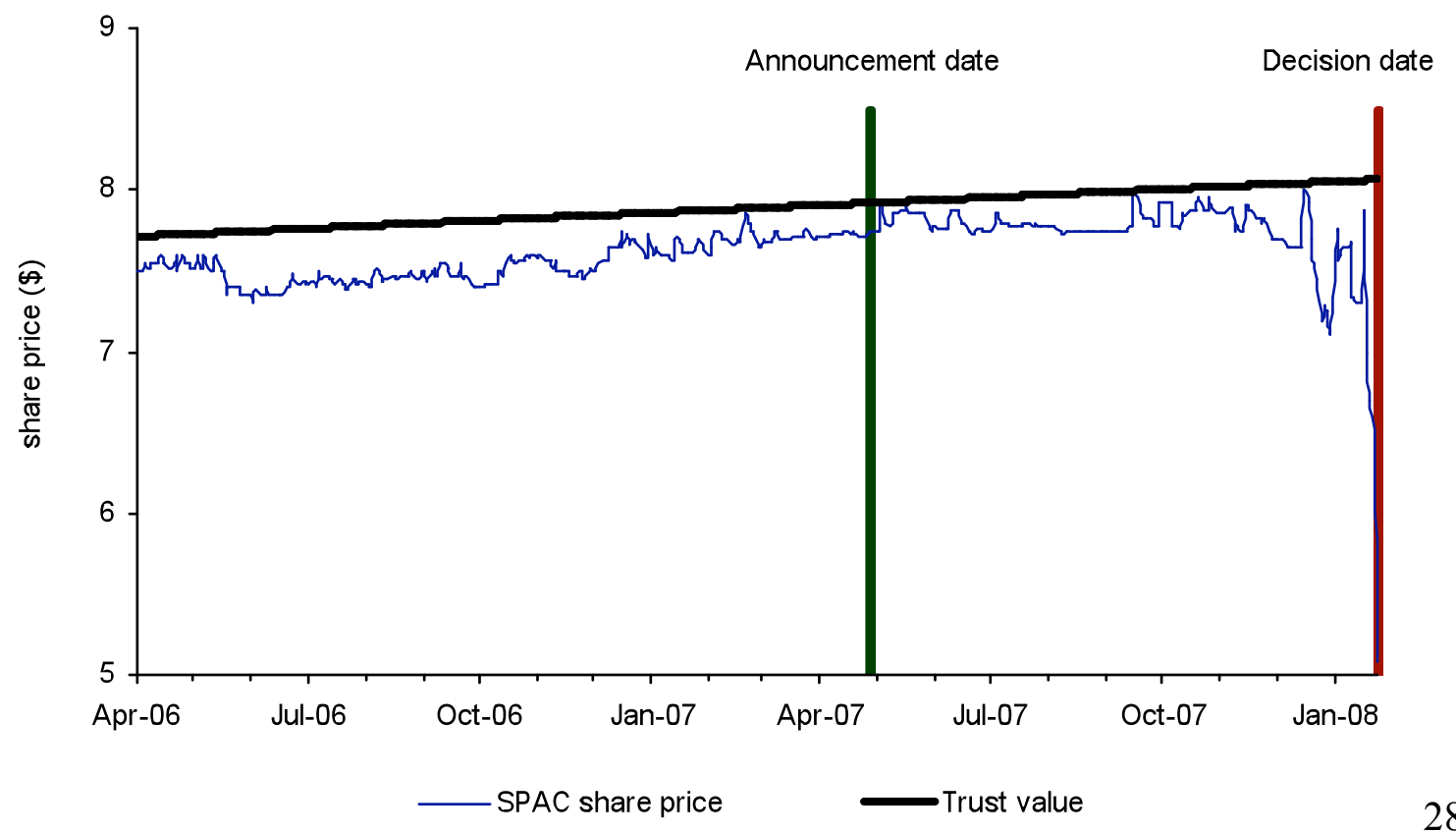




\section{Figure 5 - Share prices between the announcement and decision dates}

In this figure, the share price performance of Good and Bad SPACs are compared. If the share price was above (below) the trust value at the decision date, SPACs are classified as Good (Bad). There are 20 Good SPACs and 23 Bad SPACs. Equally-weighted price indices are created, based on the share price 3 days before the announcement date. In Panel A, the index is presented for the first 40 days after the announcement, and in Panel B the index is presented for the last 40 days before the decision date. Note that the gap between the announcement and decision dates varies across the sample.

\section{Panel A: After the announcement date}

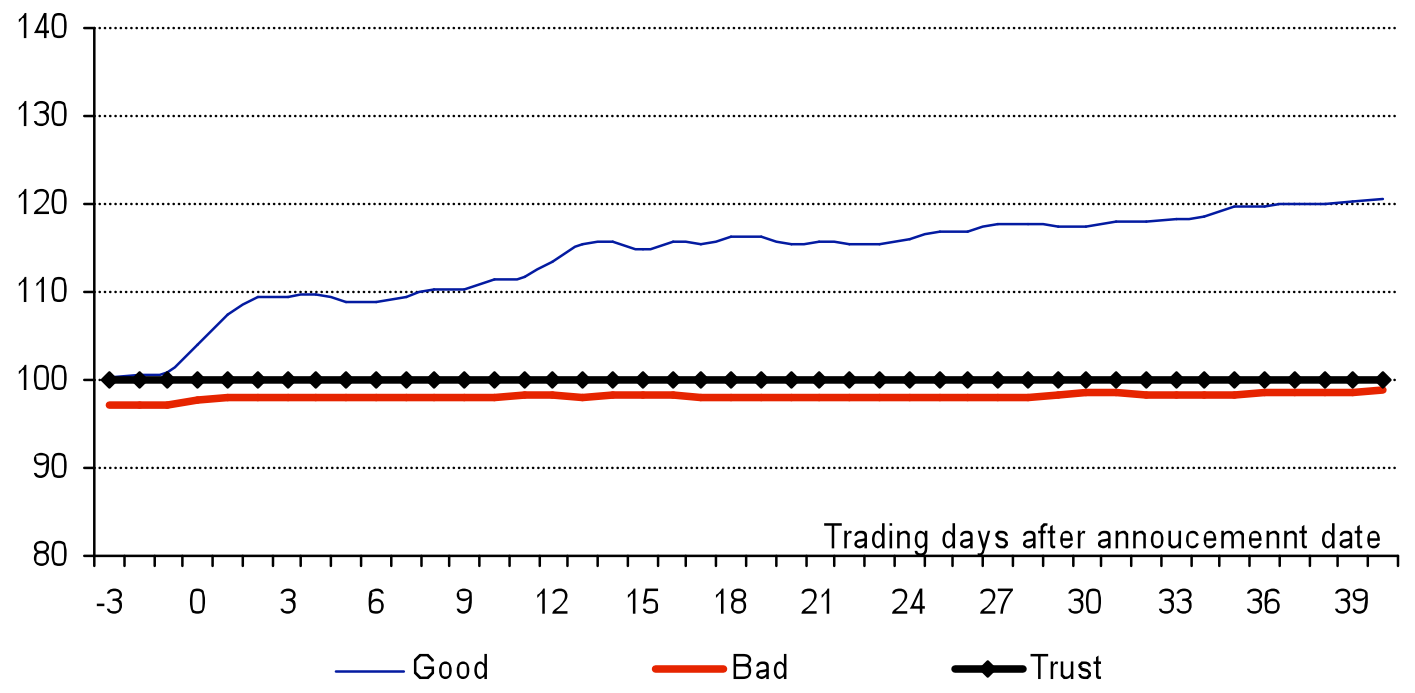

Panel B: Before the decision date

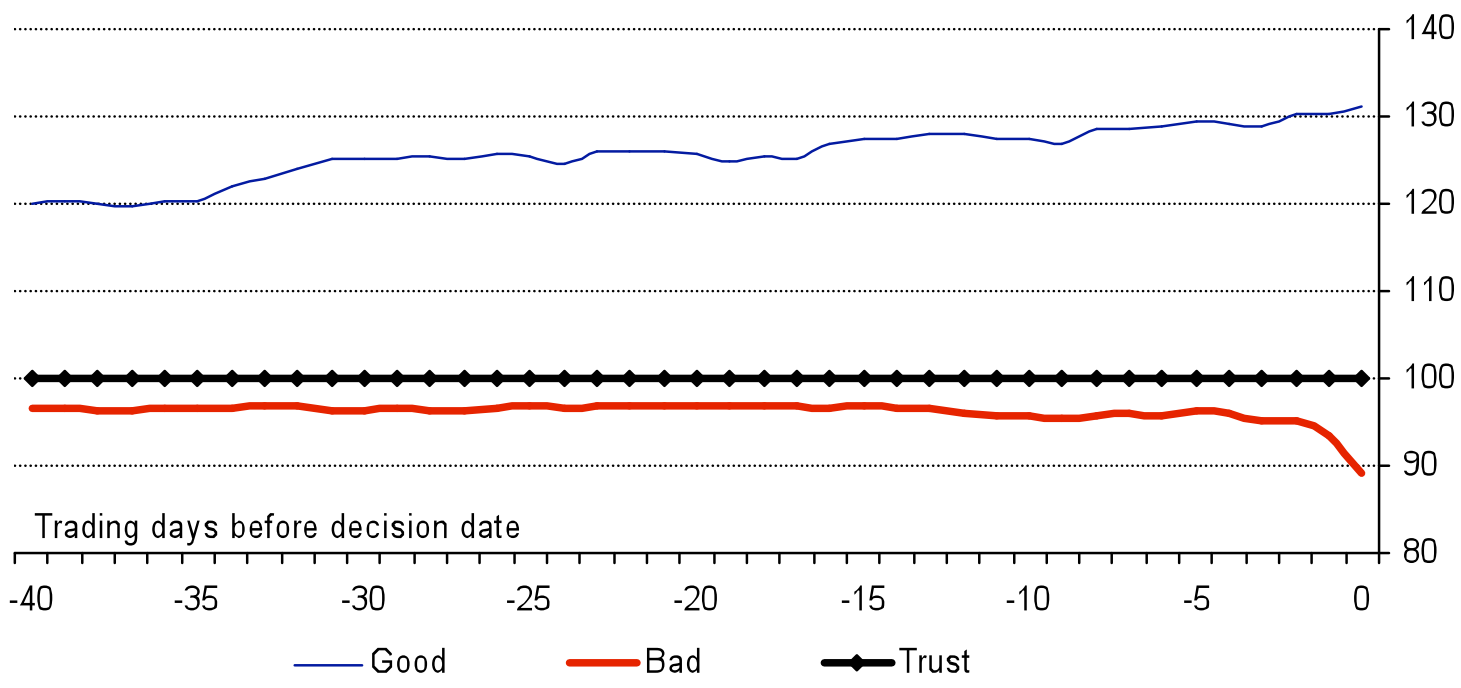




\section{Figure 6- Post-Acquisition Returns}

In this figure, the share price performance of Good and Bad SPACs are compared in the 26-week period after the acquisition was approved. If the share price was above (below) the trust value at the decision date, SPACs are classified as Good (Bad). There are 20 Good SPACs and 23 Bad SPACs. All returns are based on weekly data and are equally-weighted. In Panel A raw returns are presented for each group. In Panel B, cumulative abnormal returns (CARs) are computed using the CAPM model, with betas estimated using industry averages for each SPAC, and also assumed to be unity in each case.

\section{Panel A: Raw returns}

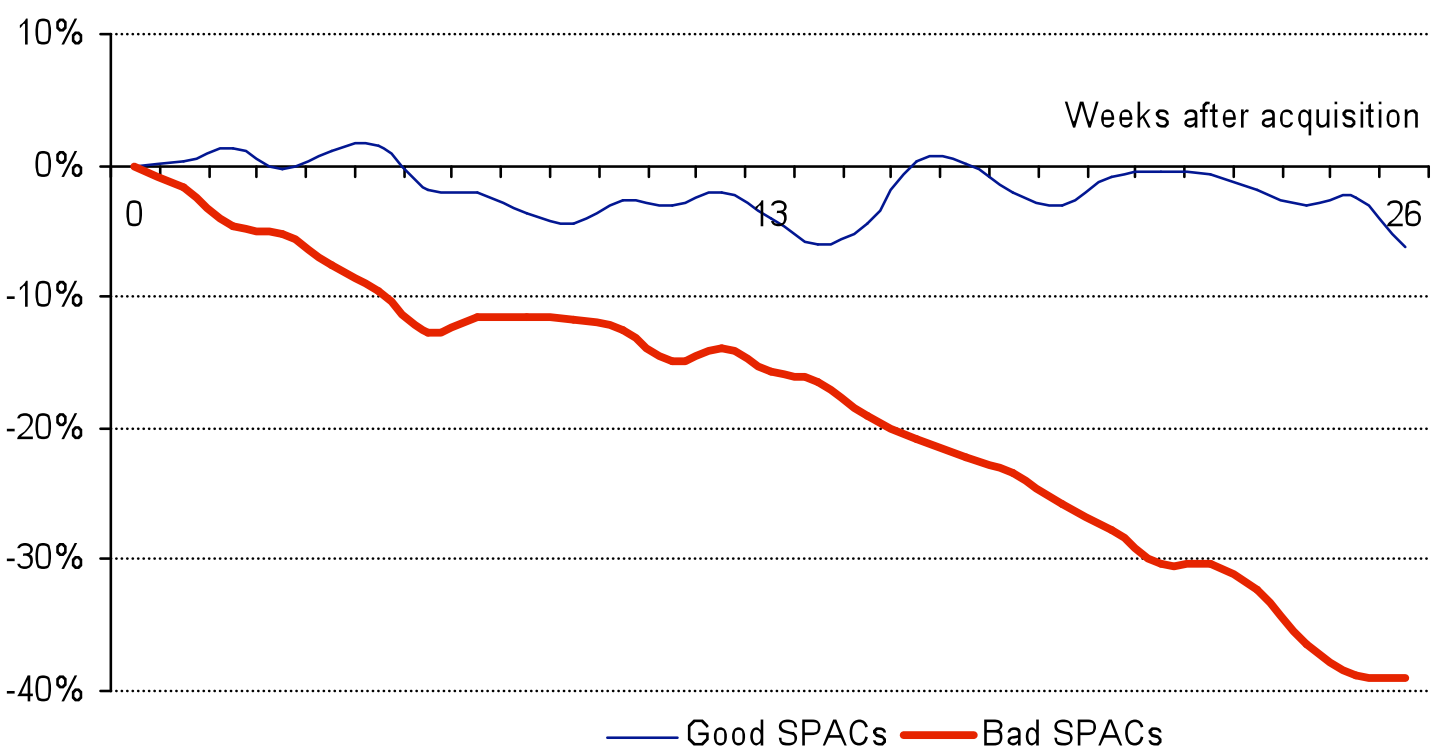

Panel B: Cumulative Abnormal Returns

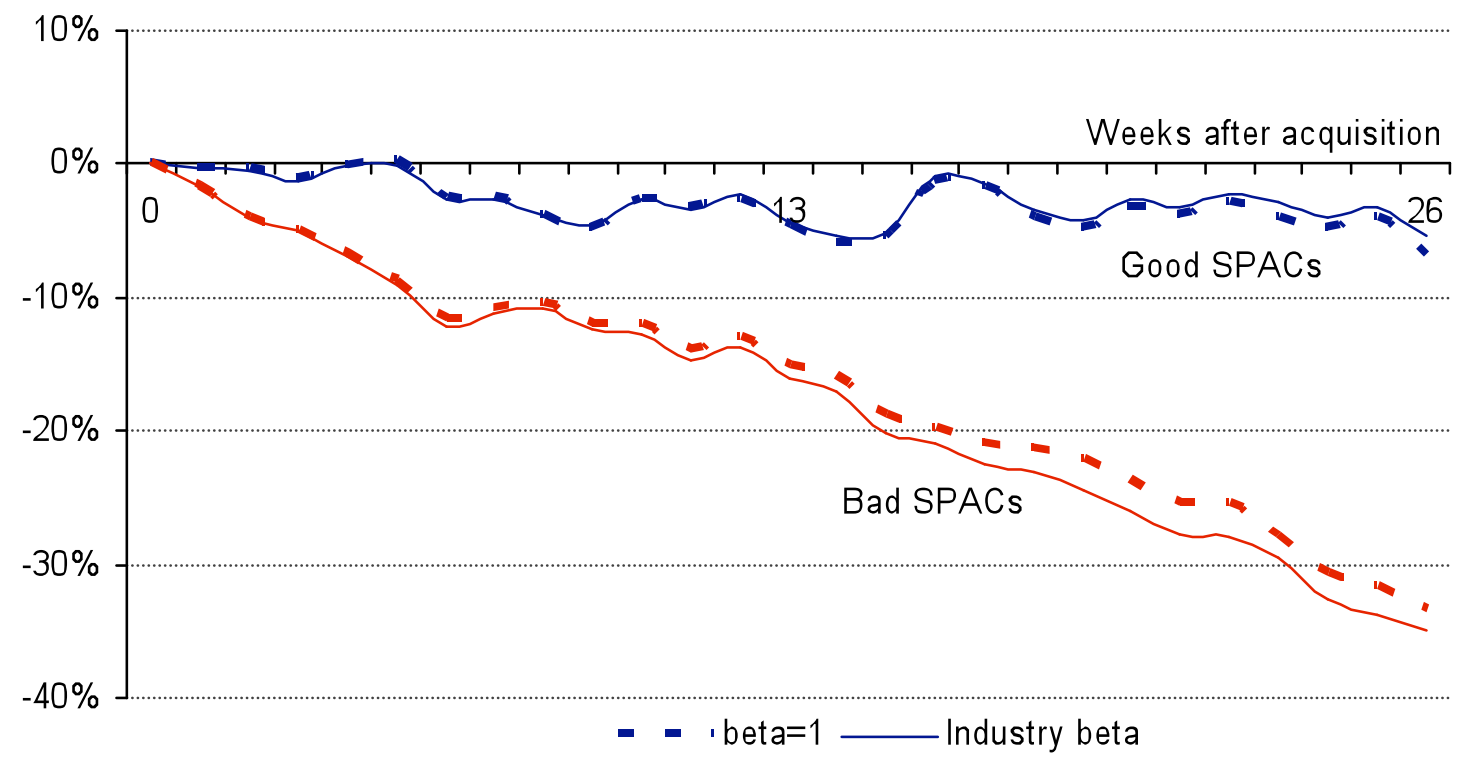




\section{Figure 7 - Turnover around the decision date}

This figure shows the average turnover (shares trading over shares offered in the initial public offering) for Good and Bad SPACs over the last forty trading days before the decision date. If the share price was above (below) the trust value at the decision date, SPACs are classified as Good (Bad). There are 20 Good SPACs and 23 Bad SPACs.

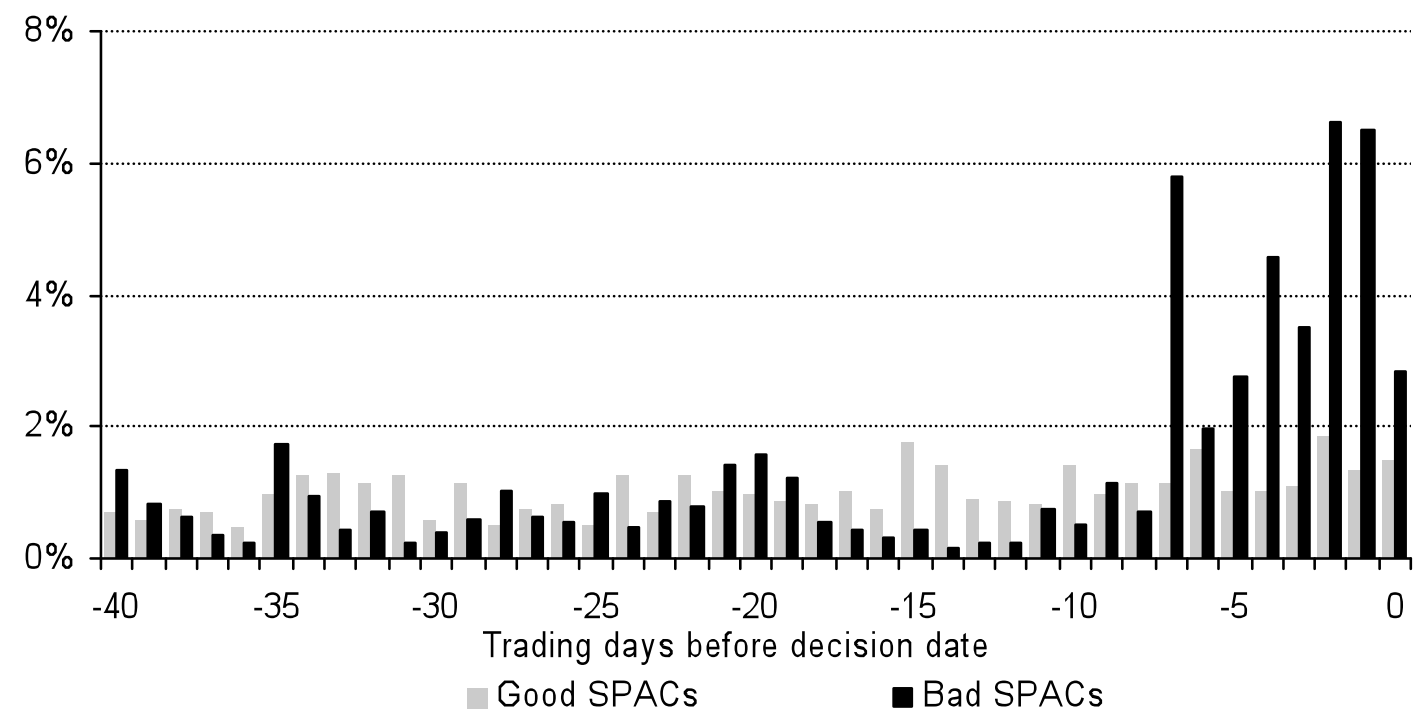




\section{Figure 8- Intraday transactions}

This figure shows the size and price for the trades involving 12 of the 16 SPACs for which TAQ data is available in the last days before (in alternating blue) and on (in red) the decision date, along with the actual trust value per share. The figure also reports (when significant) the daily turnover. Panels A, B and C show the trades involving SPACs that were liquidated, Good SPACs and Bad SPACs respectively.

PANEL A - Liquidated SPACs

\section{A.1 - Grubb \& Ellis Realty Advisors, Inc.}

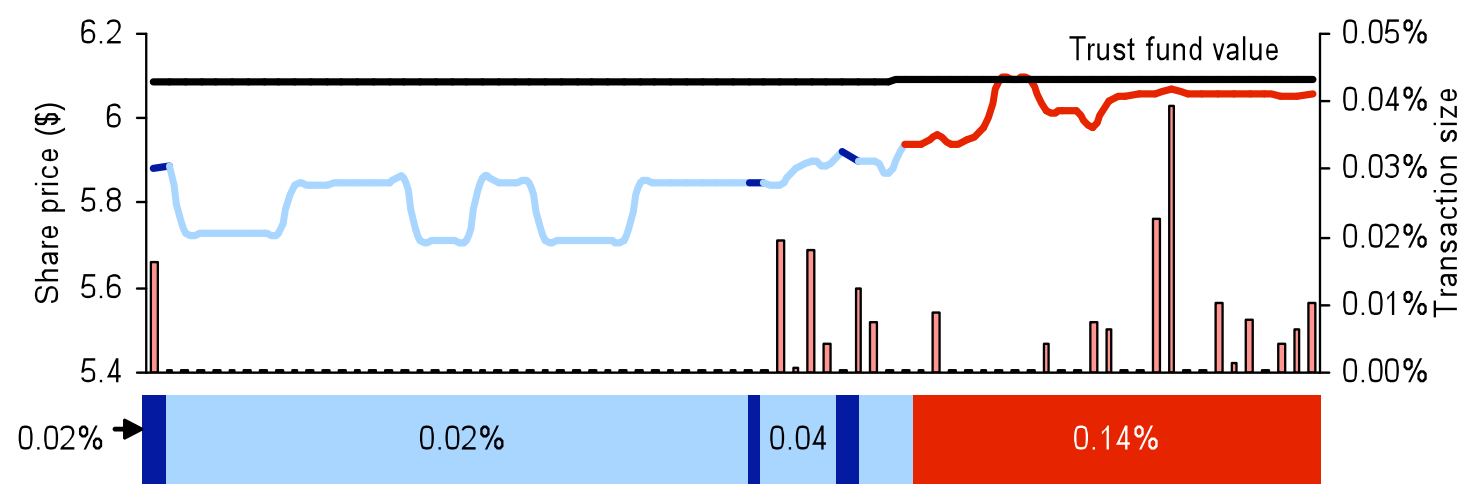

A.2 - Shanghai Century Acquisition Corp.

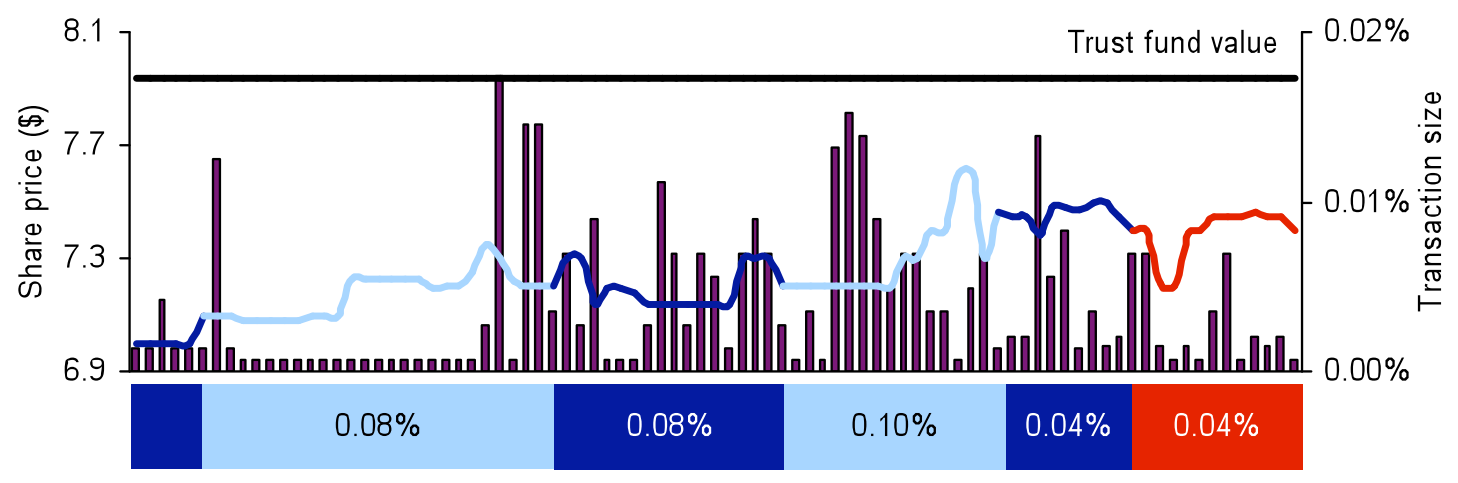

A.3 - Harbor Acquisition Corp.

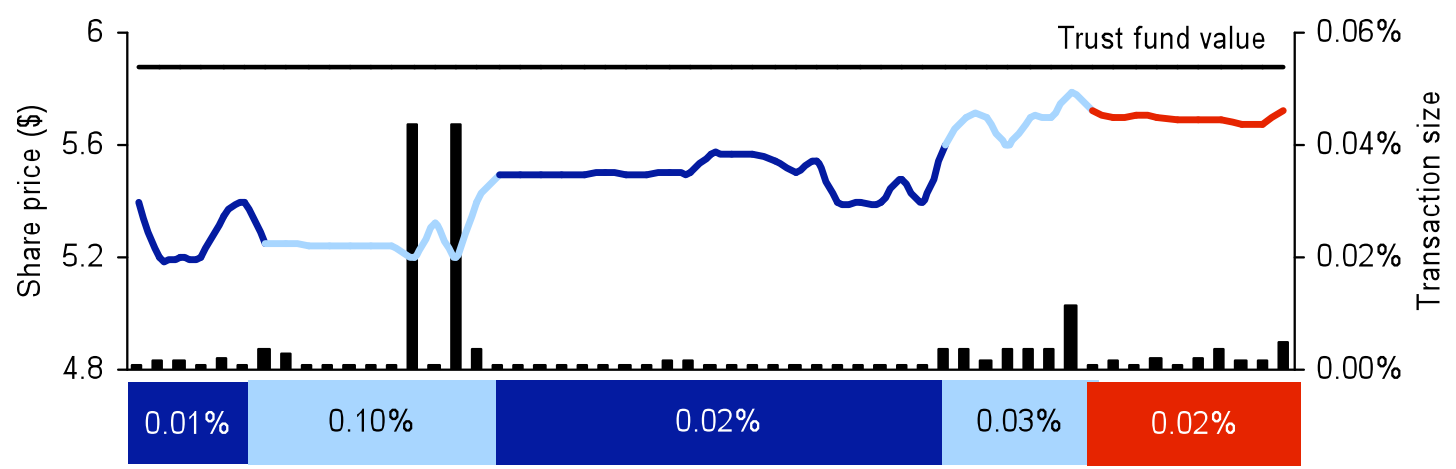


PANEL B - Good SPACs

B.1 - Star Maritime Acquisition Corp. (Star Bulk Carriers Corp.)

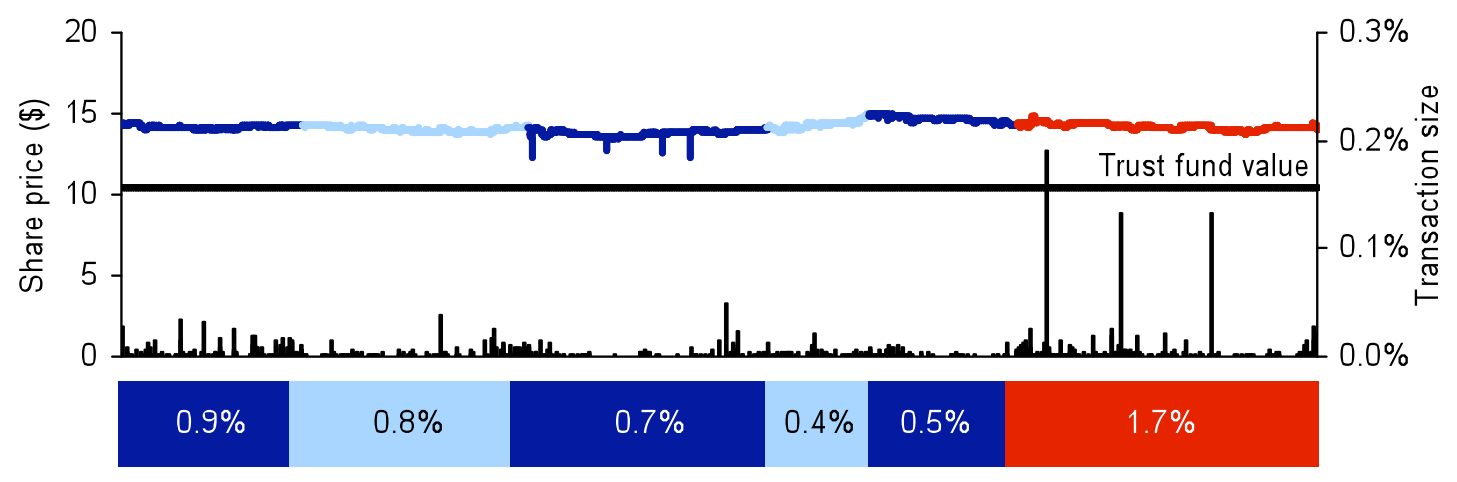

B.2 - Endeavor Acquisition Corp. (American Apparel, Inc.).

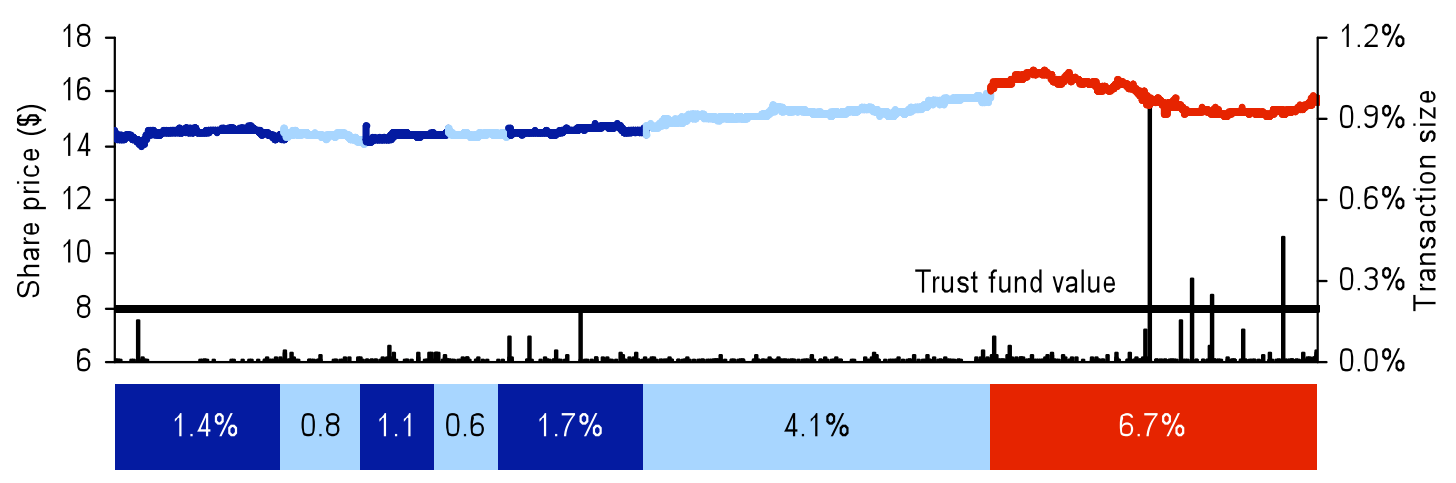

B.3 - Services Acquisition Corp. International (Jamba, Inc.)

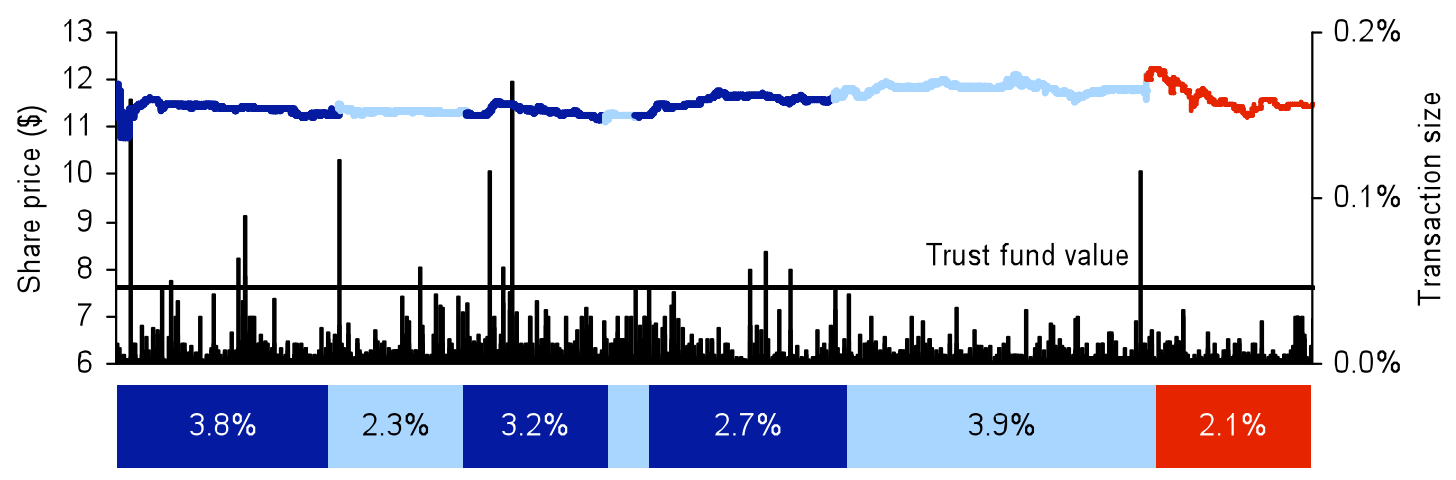


PANEL C - Bad SPACs

C.1 - Courtside Acquisition Corp (American Community Newspapers Inc.)

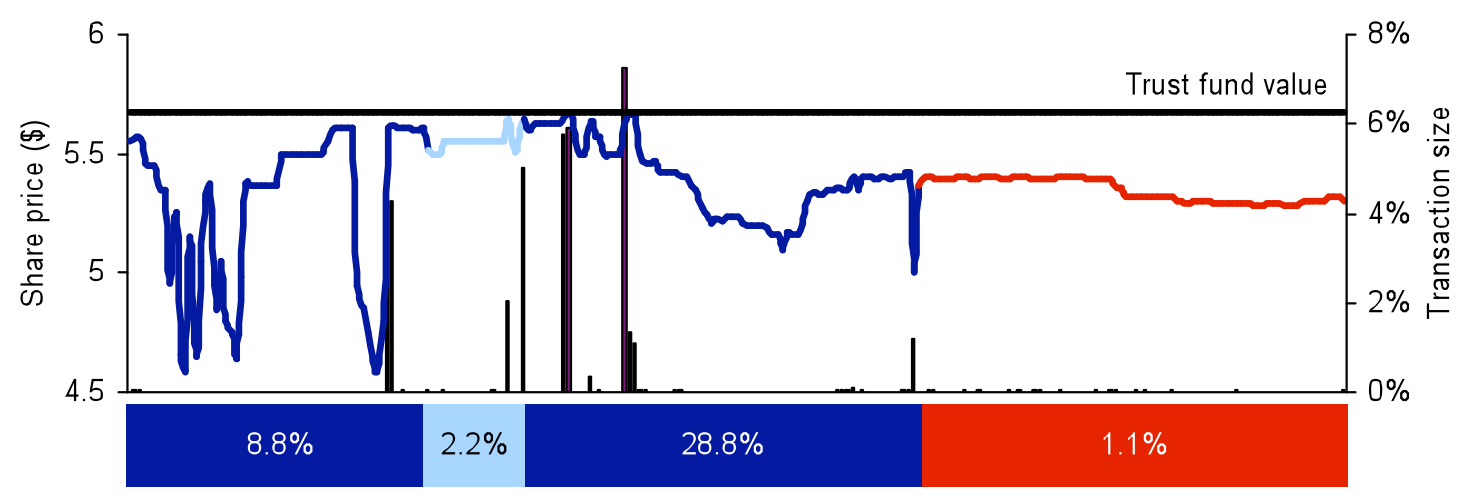

C.2 - Acquicor Technology, Inc. (Jazz Technologies, Inc.).

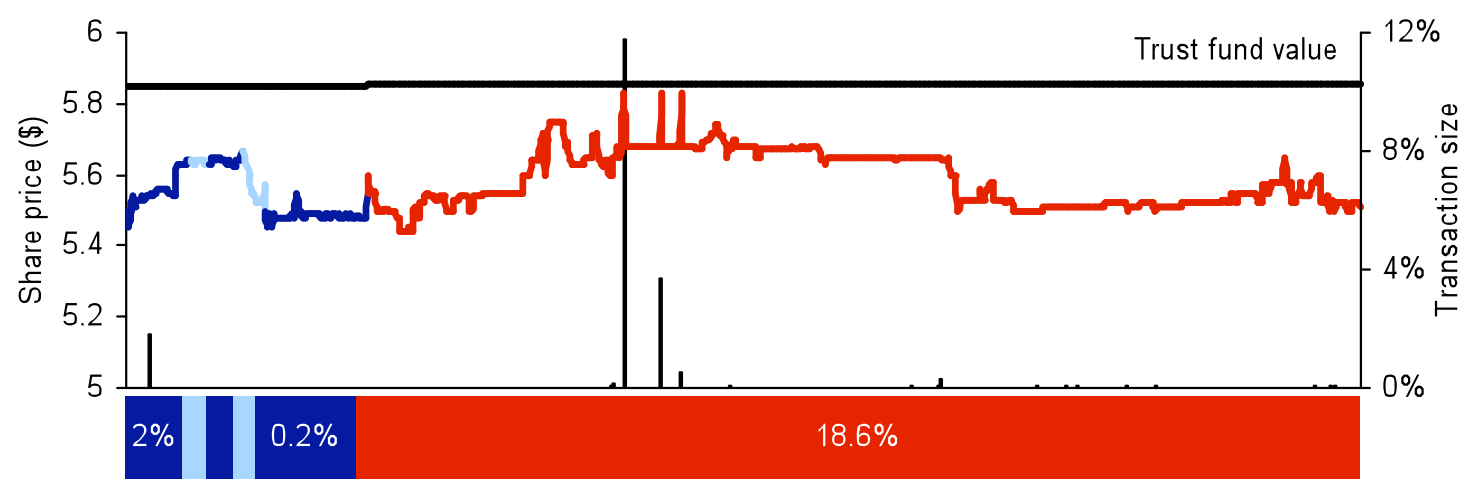

C.3 - Healthcare Acquisition Corp. (PharmAthene, Inc.)

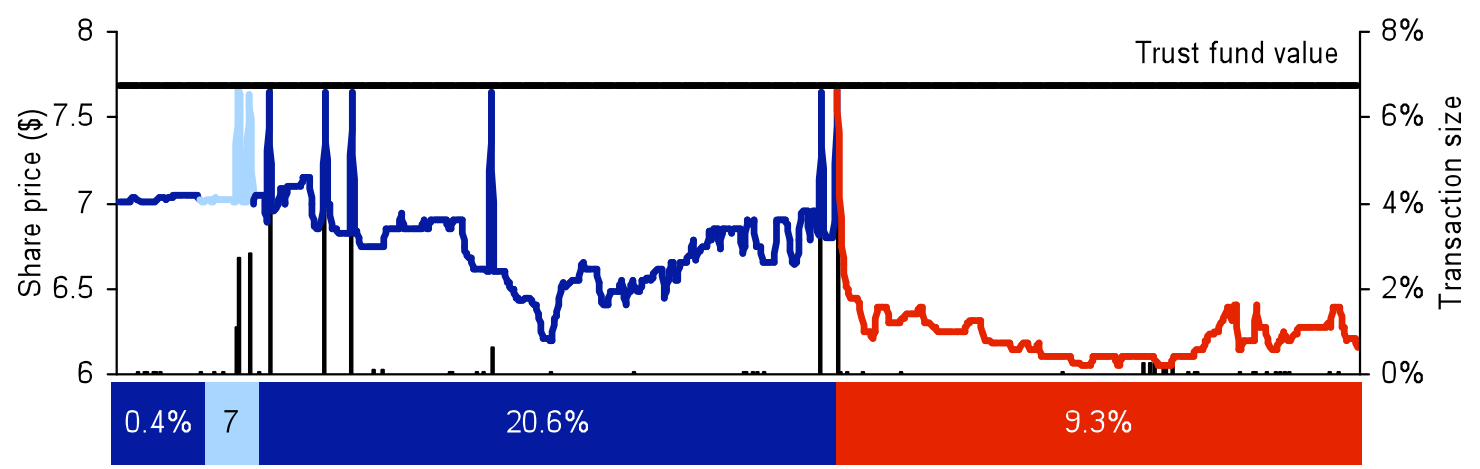




\section{C.4 - Global Logistics Acquisition Corp. (Clark Holdings Inc.)}

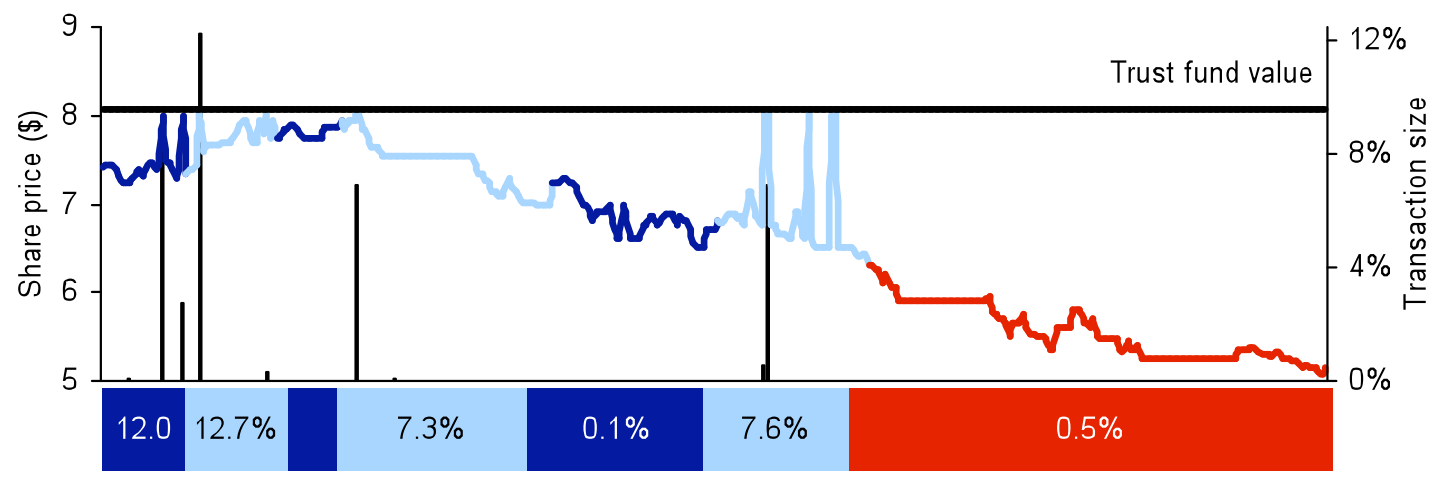

\section{C.5 - General Finance Corporation}

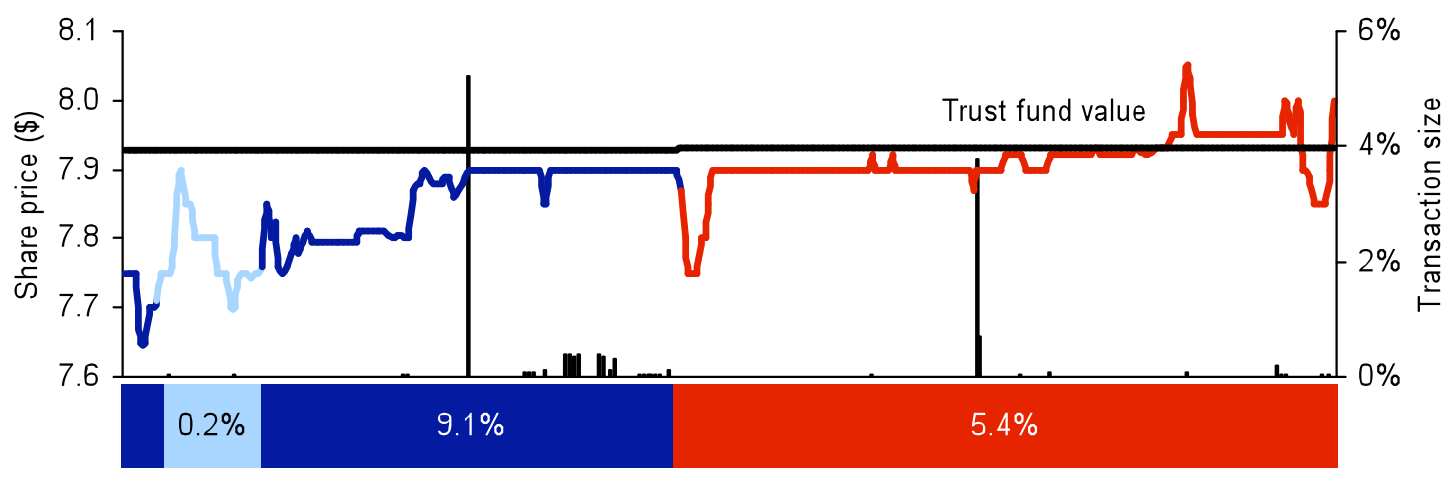

C.6 - Community Bankers Trust Corporation

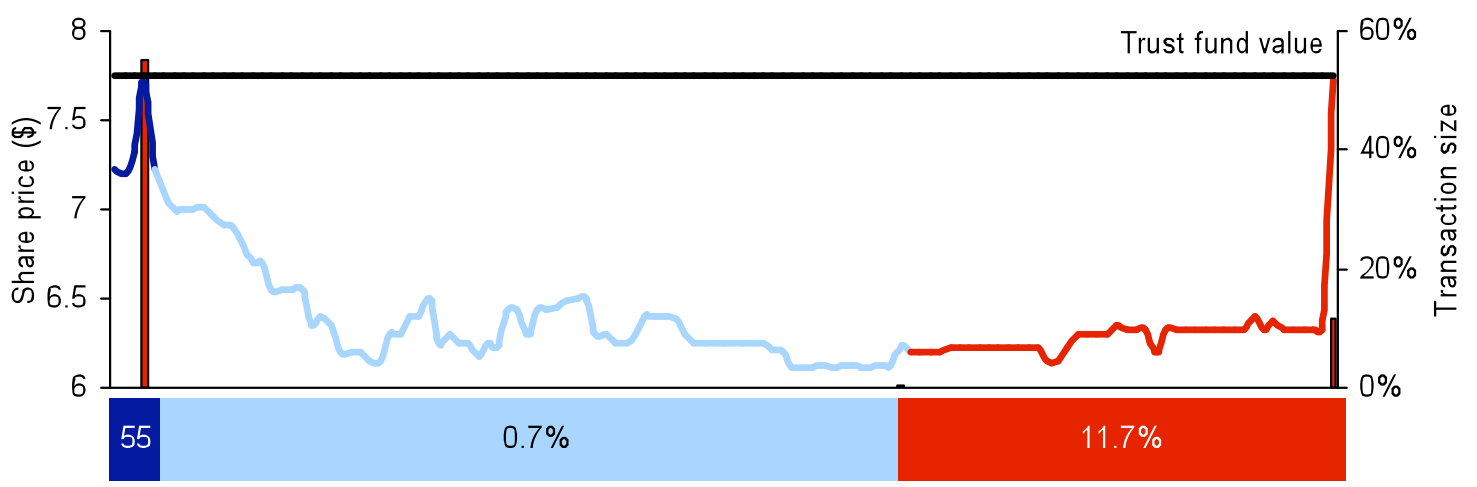

